This item was submitted to Loughborough's Research Repository by the author.

Items in Figshare are protected by copyright, with all rights reserved, unless otherwise indicated.

\title{
Advanced spectroscopic analyses on a: C-H materials: Revisiting the EELS characterization and its coupling with multi-wavelength Raman spectroscopy
}

\section{PLEASE CITE THE PUBLISHED VERSION}

http://dx.doi.org/10.1016/j.carbon.2016.10.092

\section{PUBLISHER}

(C) Elsevier

VERSION

AM (Accepted Manuscript)

\section{PUBLISHER STATEMENT}

This work is made available according to the conditions of the Creative Commons Attribution-NonCommercialNoDerivatives 4.0 International (CC BY-NC-ND 4.0) licence. Full details of this licence are available at: https://creativecommons.org/licenses/by-nc-nd/4.0/

\section{LICENCE}

CC BY-NC-ND 4.0

\section{REPOSITORY RECORD}

Lajaunie, L., C. Pardanaud, C. Martin, P. Puech, C. Hu, Mark J. Biggs, and R. Arenal. 2019. "Advanced Spectroscopic Analyses on A: C-H Materials: Revisiting the EELS Characterization and Its Coupling with Multiwavelength Raman Spectroscopy". figshare. https://hdl.handle.net/2134/23128. 


\title{
Advanced Spectroscopic Analyses on a:C-H Materials: Revisiting the EELS Characterization and its Coupling with multi-wavelength Raman Spectroscopy
}

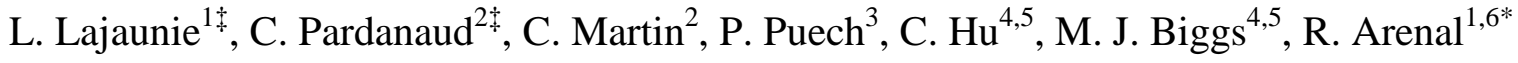 \\ ${ }^{1}$ Laboratorio de Microscopias Avanzadas (LMA), Instituto de Nanociencia de Aragon, \\ Universidad de Zaragoza, 50018 Zaragoza, Spain \\ ${ }^{2}$ Aix-Marseille Université,CNRS, PIIM, Marseille, France \\ ${ }^{3}$ CEMES, Toulouse, France \\ ${ }^{4}$ School of Chemical Engineering, The University of Adelaide, SA 5005, Australia \\ ${ }^{5}$ School of Science, Loughborough University, Loughborough, LE11 3TU, UK \\ ${ }^{6}$ Fundacion ARAID, 50018 Zaragoza, Spain \\ * Corresponding author: Tel: +34 976762 985, E-mail address: $\underline{\text { arenal@unizar.es }}$ \\ $\ddagger$ These authors contributed equally
}

\begin{abstract}
Hydrogenated amorphous carbon thin films (a:C-H) are very promising materials for numerous applications. The growing of relevance of a:C-H is mainly due to the long-term stability of their outstanding properties. For improving their performances, a full understanding of their local chemistry is highly required. Fifteen years ago, electron energy-loss spectroscopy (EELS), developed in a transmission electron microscope (TEM), was the technique of choice to extract such kind of quantitative information on these materials. Other optical techniques, as Raman spectroscopy, are now clearly favored by the scientific community. However, they still lack of
\end{abstract}


the spatial resolution offered by TEM-EELS. In addition, nowadays, the complexity of the physics phenomena behind EELS is better known. Here, a:C-H thin films have been isothermally annealed and the evolution of their physical and chemical parameters have been monitored at the local and macroscopic scales. In particular, chemical in-depth inhomogeneities and their origins are highlighted. Furthermore, a novel procedure to extract properly and reliably quantitative chemical information from EEL spectra is presented. Finally, the pertinence of empirical models used by the Raman community is discussed. These works demonstrate the pertinence of the combination of local and macroscopic analyses for a proper study of such complex materials.

\section{Introduction}

Hydrogenated amorphous carbon (a-C:H) thin films constitute a mix, at the local scale, of $\mathrm{sp}^{2}$ clusters and $\mathrm{sp}^{3}$ carbon domains with different contents of $\mathrm{H}$. The physical and chemical properties of these films are strongly governed by on the balance between the $\mathrm{sp}^{2}$ clustering and $\mathrm{H}$ defects [1,2]. The high stability of these materials makes them very suitable for a large range of applications including the use as protecting coatings for data storage devices in order to preserve both magnetic discs and recording heads from corrosion and wear [3-5]. Recently there is a renewed interest for these materials as they exhibits a superlow friction coefficient and long wear life in ultra-high vacuum which makes them one of the most promising solid lubricant coating candidate for aerospace applications [6-10]. The origin of the superlow friction is still under investigation but seems to be closely related to the passivation of the surface by the hydrogen and to the $\mathrm{sp}^{3}$ to $\mathrm{sp}^{2}$ rehybridization [8-11]. The proper characterization of the hydrogen content together with the $\mathrm{sp}^{2}$ fraction is thus of particular importance. These coatings 
need also to be thermally stable and changes in a-C:H local chemistry during thermal annealing have then regained an interest these last few years [3,4,12-22].

Due to the extremely good sensitivity on structural modifications involving $\mathrm{sp}^{2}$ carbons, Raman spectroscopy analysis has been associated to most of the last studies on a:C-H materials $[3,4,17,19,23-30]$. The reason behind this high sensitivity is the resonance phenomena between the laser wavelength excitation used and a local band gap of a given $\mathrm{sp}^{2}$ cluster in the amorphous carbon. As $\mathrm{sp}^{2}$ clusters in amorphous carbon display inhomogeneous structural and topological disorders at the nanometric scale, their band gaps are modified subsequently [31]. Then, Raman spectra of amorphous carbons depend on clustering of the $\mathrm{sp}^{2}$-phase, bond length and bond-angle disorder, presence of $\mathrm{sp}^{2}$ rings and chains, $\mathrm{sp}^{2} / \mathrm{sp}^{3}$ ratio and inhomogeneity [23,24,27]. The optical band gap for amorphous carbon films is inversely related to the aromatic cluster size and the disorder potential of the samples [2,31,32]. Because of that, multi-wavelength Raman spectroscopy has been used on various $\mathrm{sp}^{2}$ carbon containing materials to obtain information on the structure ranging from amorphous carbons or soots, to graphene or carbon nanotubes [2326,28,33-40]. However, Raman spectroscopy presents some limitations for getting directly this chemical information from these materials at the local scale. Thus, in addition of this spectroscopic technique, electron energy-loss spectroscopy (EELS) performed in a (Scanning) transmission electron microscope ((S)TEM) is a complementary technique, which gives access to a wealth of structural, chemical and physical information with nanometer to sub-angstrom spatial resolution [41-47]. Analysis of core-loss EELS spectra yields qualitative and quantitative information on the elemental composition and on the local chemical environment (bonding configuration, valence state...) [48-52]. The fine structures of the C-K edge can be used to distinguish the different carbon allotropes [41,45,48,53-55]. The sharp peak at $285 \mathrm{eV}$ 
corresponding to transitions to $\pi^{*}$ states (Fig. 1) is observed in the graphite spectrum but not in the diamond spectrum, the transitions to $\sigma^{*}$ states appearing at higher energy (around $292 \mathrm{eV}$ ) $[48,56]$. Beyond this qualitative description, the $\mathrm{sp}^{2}$ fraction can also be determined from thorough analysis of the C-K edge [57-60]. However, the determination of the $\mathrm{sp}^{2}$ fraction of carbon-based materials from core-loss EELS is not an easy task and two main pitfalls should be avoided. The first one lies in the modeling of the $\pi^{*}$ and $\sigma^{*}$ components of the C-K edge spectrum (i.e. the determination of the $R$ ratio) and the second one concerns the structural and electronic anisotropy of these $\mathrm{sp}^{2}$ carbon materials. Regarding this first limitation, most of the models in the literature use an improper combination of Gaussian and/or Lorentzian functions [61,62], whereas ab-initio calculations have shown that the $\pi^{*}$ component is asymmetric and spreads out several dozens of eV after the edge threshold [60,63]. As a direct consequence, models using a combination of Gaussian and/or Lorentzian functions need to add another artificial component to compensate the real asymmetry of the $\pi^{*}$ character $[61,62,64]$. Others methods based on the integration of two-windows are inappropriate from a chemical point-of view as they do not consider all the transitions present in the EELS spectra and thus failed to take into account the contribution of heretrospecies $[65,66]$. The next step to determine the $\mathrm{sp}^{2}$ fraction requires the determination of the $\pi^{*}$ and $\sigma^{*}$ spectral weights from a reference sample showing $100 \% \mathrm{sp}^{2}$ bonding and in the same experimental conditions [58,67]. Graphite is then the ideal reference sample. However, it is an anisotropic material and the second pitfall lies in the sensitivity of the EELS spectra to the anisotropy of the material $[45,46,55,68-73]$.

The spectral weight of the $\pi^{*}$ and $\sigma^{*}$ components of anisotropic carbon-base materials depends then strongly on the specimen orientation and on the convergence and collection angles [68-70,74]. A particular setup of convergence and collection angles can be used to alleviate the 
dependence of the C-K edge spectrum with the specimen orientation (the so-called magic-angle condition) [68-72,75]. The collection angle at magic angle condition for an energy-loss of 290 $\mathrm{eV}$ should be $4.9 \mathrm{mrad}$ at $80 \mathrm{kV}, 1.2 \mathrm{mrad}$ at $200 \mathrm{kV}$ and $0.7 \mathrm{mrad}$ at $300 \mathrm{kV}$. At the highest voltage, the magic angle condition for carbon is then nearly impossible to attain while at lower voltage, in particular in STEM mode, a larger collection angle is needed to ensure a good signal/noise ratio. Fifteen years ago, according to the seminal work of Ferrari et al. [57], EELS was technique of choice to get quantitative information on the local chemistry of a-C:H materials. Nowadays, our knowledge of the physics phenomena behind the EEL spectroscopy has considerably improved, but surprisingly, this technique is now regarded as time-consuming and difficult to properly interpret. Under these circumstances, the community has favored the use of Raman spectroscopy. In the present work, we will show the pertinence of EELS and the coupling of this technique with Raman spectroscopy for obtaining the maximum information of these materials. In particular, the goals of these studies are, not only to get more insight on the local chemistry of a-C:H thin films, but also to provide some guidance regarding their characterizations by EELS and Raman spectroscopies.

In this paper, we investigated the modifications followed by a-C:H thin films on silicon substrate during long-term isothermal annealing periods, up to $2500 \mathrm{~min}$. This paper is divided as follows. In section 2, the Raman and EELS methodologies are presented and a novel method to determine the $\mathrm{sp}^{2}$ fraction from core-loss EELS is deeply described. A general overview of the Raman and EELS spectra are given in section 3. The evolution of physical and chemical parameters as function of the annealing time are discussed from a macroscopic point of view in section 4, together with their evolutions as a function of the distance between the electron probe and the substrate. Finally, the pertinence of empirical models used by the Raman community for 
quantitatively linking the $\mathrm{sp}^{2}$ fraction with the evolution of Raman parameters $[29,30]$ will be reviewed. To sum up, these works demonstrate and illustrate the perfect coupling of these local and macroscopic analyses for a proper study of such complex materials.

\section{Materials and methods}

\subsection{Materials}

A hard amorphous, hydrogenated carbon film (a-C:H), with a thickness around $300 \mathrm{~nm}$ and an initial hydrogen content $(\mathrm{H} / \mathrm{H}+\mathrm{C})$ of 30 at. \%, was deposited on a Si wafer on the driven electrode of a capacitively coupled radio frequency plasma $(13.56 \mathrm{MHz})$ in pure methane at $2 \mathrm{~Pa}$ and a DC self-bias of -200V [17,76]. To vary the hydrogen content and structure, the layer was cut in several samples that were heated under 1.5 bar argon atmosphere at $500^{\circ} \mathrm{C}$ during $\mathrm{t}=2$, 15, 60, 120, 500, 1000 and 1500 minutes. For Raman spectroscopy analysis, a set of reference samples (heated from room temperature to $1000{ }^{\circ} \mathrm{C}$ under ultra-high vacuum, with $\mathrm{H}$ content measured by ion beam analysis and described in detail in [19]) has also been used for comparison. The attenuated total reflectance (ATR) infrared spectra of the different samples were taken with a Bruker IFS 66/S spectrometer, which was purged with dry air. The samples were used without further purification and they have been ground before measurement. The ATR spectra were recorded using a diamond or a germanium ATR crystal and a deuterated triglycine sulfate detector. A resolution of $2 \mathrm{~cm}$ was used.

TEM samples were prepared in the cross-section geometry; they were mechanically thinned using a tripod polisher down to $10 \mu \mathrm{m}$, and then ion-milled in a GATAN-PIPS apparatus at low energy $(2.5 \mathrm{keV}, \mathrm{Ar})$ and low incidence $\left( \pm 8^{\circ}\right)$ to minimize irradiation damage. It should be noted that ionic irradiation of amorphous carbon at such low energy should not alter 
significantly the surface of the sample [77].Highly ordered pyrolytic graphite (HOPG) samples were also prepared for EELS analysis by ultrasonic vibration in pure ethanol during ten minutes.

\subsection{Multi-wavelength Raman set-ups and data treatment}

Multi-wavelength Raman spectra, with laser wavelength $\lambda_{\mathrm{L}}=633$, 514, 407, 325 and 266 $\mathrm{nm}$, were obtained at room temperature, using three different set up. For $\lambda_{\mathrm{L}}=633,514$ and 325 nm, Raman spectra were obtained in a Horiba-Jobin-Yvon HR LabRAM spectrometer. For $\lambda_{\mathrm{L}}=$ $407 \mathrm{~nm}$, Raman spectra were obtained in a T64000 Horiba-Jobin-Yvon apparatus. For $\lambda_{\mathrm{L}}=266$ nm, Raman spectra were also obtained with a Horiba-Jobin-Yvon HR Labram spectrometer. The objective lens was a 40x magnification. The detector was a Horiba Jobin-Ivon Synapse charged coupled device detection system. To avoid irradiation damage at $266 \mathrm{~nm}$ excitation wavelength, $\mathrm{a} \sim 1 \mu \mathrm{m}^{2}$ laser spot was scanned over the sample on a 60x60 $\mu \mathrm{m}^{2}$ area has been employed. The scanning time was 1 second per spectrum. We applied a similar procedure for the $\lambda_{\mathrm{L}}=325 \mathrm{~nm}$ radiation. The laser power was chosen sufficiently low to prevent damaging of the samples (roughly $1 \mathrm{~mW}_{\mu \mathrm{m}^{-2}}$ on the sample) but sufficiently high to have a good signal to noise ratio.

The main Raman parameters analyzed were: the $G$ peak wavenumber $\left(\sigma_{G}\right)$ and its fullwidth at half-maximum $\left(\Gamma_{G}\right)$ the relative heights of the $G$ and $D$ bands $\left(\mathrm{H}_{\mathrm{D}} / \mathrm{H}_{\mathrm{G}}\right)$ and the $\mathrm{m} / \mathrm{H}_{\mathrm{G}}$ ratio, where $\mathrm{m}$ is the slope of the photoluminescence background of the spectra. Concerning the different parameters, $\sigma_{\mathrm{G}}$ gives information on the structural disorder and/or clustering, $\Gamma_{\mathrm{G}}$ gives information on the topological disorder, $\mathrm{H}_{\mathrm{D}} / \mathrm{H}_{\mathrm{G}}$ and $\mathrm{m} / \mathrm{H}_{\mathrm{G}}$ gives mainly information on the $\mathrm{H}$ content $[3,19]$. A linear background was subtracted and heights $H_{D}$ and $H G$ were measured without any fitting to prevent from ambiguousness due to a model-dependent fitting procedure $[18,19]$. This last choice was done because a debate still exists in the literature concerning how to fit properly amorphous carbon Raman spectra $[1,30,78,79] . H_{D}$ was therefore measured at its 
apparent maximum, except when the D band maximum was not well enough defined. For these samples $\mathrm{H}_{\mathrm{D}}$ was taken arbitrarily at $1370 \mathrm{~cm}^{-1}$.

\subsection{EELS acquisition and data treatment}

EELS spectra were acquired on a FEI Tecnai F30 operating at $300 \mathrm{kV}$ and equipped with a Gatan Tridiem 863 spectrometer. Convergence and collection angles were 6.1 and $5.9 \mathrm{mrad}$, respectively. To minimize carbon contamination and irradiation beam damage, experiments were performed at liquid nitrogen temperature. For the same reasons, the probe, of 1-2 nm, was constantly rastering a square area of $20 \mathrm{~nm} \times 20 \mathrm{~nm}$ during the EELS acquisition. The rastering speed was $2 \mu \mathrm{s} /$ pixel. The size of the rastered areas was much larger than $\mathrm{sp}^{2}$ clusters size in amorphous carbons (typically a few nanometers [27]), which guarantees an EELS response independent of the orientation of the $\mathrm{sp}^{2}$ clusters. The energy resolution, measured as the full width at half maximum of the zero loss peak (ZLP), was $1.2 \mathrm{eV}$ with an energy dispersion of 0.2 $\mathrm{eV} /$ pixel and $0.9 \mathrm{eV}$ for a dispersion of $0.05 \mathrm{eV} /$ pixel. The first dispersion was used for carbon and oxygen elemental quantification and the second one for C-K edge fine-structures analysis and determination of the $\mathrm{sp}^{2}$ fraction. The typical acquisition times for $\mathrm{C}-\mathrm{K}$ edge and low-loss spectra were 20 and 0.2 seconds, respectively. At least 15 spectra per sample were acquired and processed to check the homogeneity of the samples. The spectra were also acquired at different positions from the Si substrate. Background subtraction for the C-K edge was performed by modeling the usual inverse power law function and the multiple scattering was then removed by Fourier-ratio deconvolution [41] with the low-loss spectrum obtained for exactly the same region of the sample. The maximum of the $\pi^{*}$ peak was fixed at $285 \mathrm{eV}$ to minimize systematic error from peak position. 


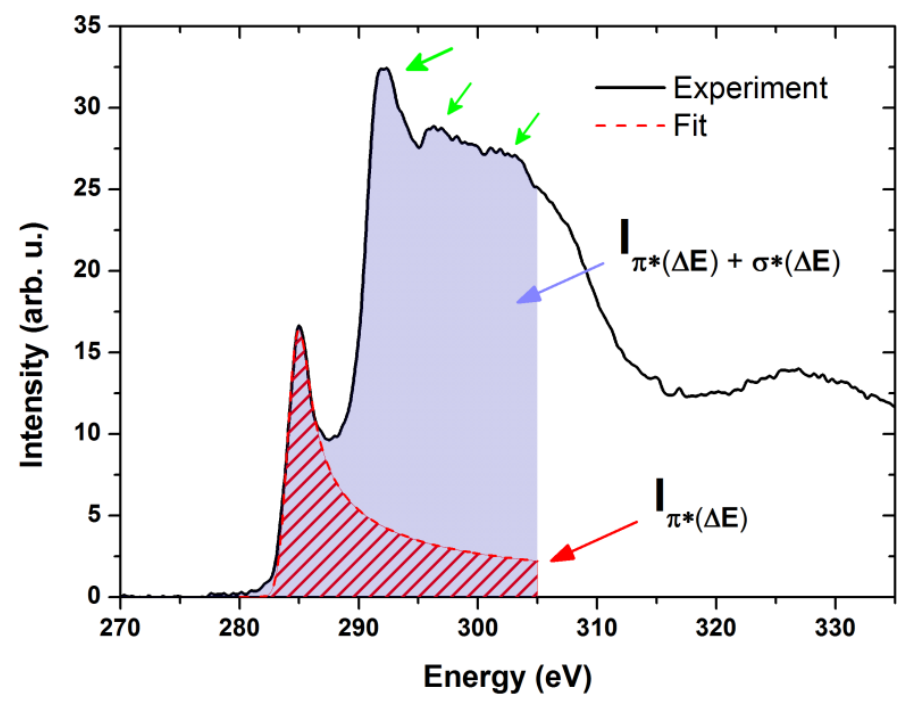

Fig. 1 EELS spectra of a graphite sample illustrating the method used to determine the $R$ ratio (see text for more details). The green arrows highlight the fine structures of the graphite spectra. (A color version of this figure can be viewed online)

The first step in the determination of the $\mathrm{sp}^{2}$ fraction requires the calculation of the $R$ ratio which is defined $\left.R=I_{\pi^{*}(\Delta E)} / I_{\left(\pi^{*}(\Delta E)+\sigma^{*}(\Delta E)\right.}\right)$, where $\mathrm{I}_{\pi^{*}(\Delta \mathrm{E})}$ and $\mathrm{I}_{\sigma^{*}(\Delta E)}$ are the spectral weights of the transitions to the $\pi^{*}$ and $\sigma^{*}$ states, respectively. The method used in this work for the determination of $R$ is illustrated in Fig. 1 and took inspiration from the work of Bernier et al. [60] in which the $\pi^{*}$ peak is modeled by using a sum of Gaussian functions of equal standard deviation and separated by $0.5 \mathrm{eV}$. Only three unknown parameters are required for this fit, the amplitude of all the Gaussian functions being constrained to match the decrease of $\pi^{*}$ contribution in the density of states of graphite. This method pursues thus the same goal than the one proposed by Titantah et al. [63]: to reproduce the $\pi^{*}$ character of the graphite C-K edge which, as highlighted by ab-initio calculations [60,63], is asymmetric and go on several dozens of eV after the edge threshold and thus overlap with the $\sigma^{*}$ states. This method has also been applied successfully to amorphous carbon with various sp ${ }^{2}$ ratios [60]. The fit was performed between 284 and $286 \mathrm{eV}$ in order to reproduce precisely the shape of the $\pi^{*}$ peak and the modeled function was then 
extended toward lower and higher energies. The integrated intensity of the $\pi^{*}$ character $I_{\pi^{*}(\Delta E)}$, was then determined by area integration of the modeled curve from 282 to $305 \mathrm{eV}$ (red hatched area in Fig. 1). The integrated intensity $\left.I_{\left(\pi^{*}(\Delta E)+\sigma^{*}(\Delta E)\right.}\right)$, corresponding to the summation of the contributions of the $\pi^{*}$ and $\sigma^{*}$ characters, was then determined by area integration of the experimental spectrum from 282 to $305 \mathrm{eV}$ (blue area in Fig. 1) in order to calculate the $R$ ratio. The precision of this method was checked on HOPG platelets priory orientated by electron diffraction and tilted away from the basal plane by the same amount of degree $\left(54.7^{\circ}\right)$. The choice of this angle will be explained in the following. This yields an $R$ ratio of $0.21 \pm 0.02$ (less than $1 \%$ of standard errors) and constitutes thus an improvement of the method of Bernier et al. [60] in which the $\sigma^{*}$ contribution is modelled by a Gaussian function centered at $292 \mathrm{eV}$ and which yields a standard error of $4 \%$ [60]. In addition, this method can be easily modified to take into account contributions from heterospecies (see Fig. S1 in the Supplementary Data). This has been tested on oxidized-graphenic nanoplatelets sample which contain $12 \%$ of oxygen [80]. In this case, the error on the determination of the $R$ ratio was estimated to be equal to $1.6 \%$. It is slightly larger than the original method due to the presence of one additional parameter. This modified method has been used for the samples annealed 1000 and 2500 minutes (section 4.2). 


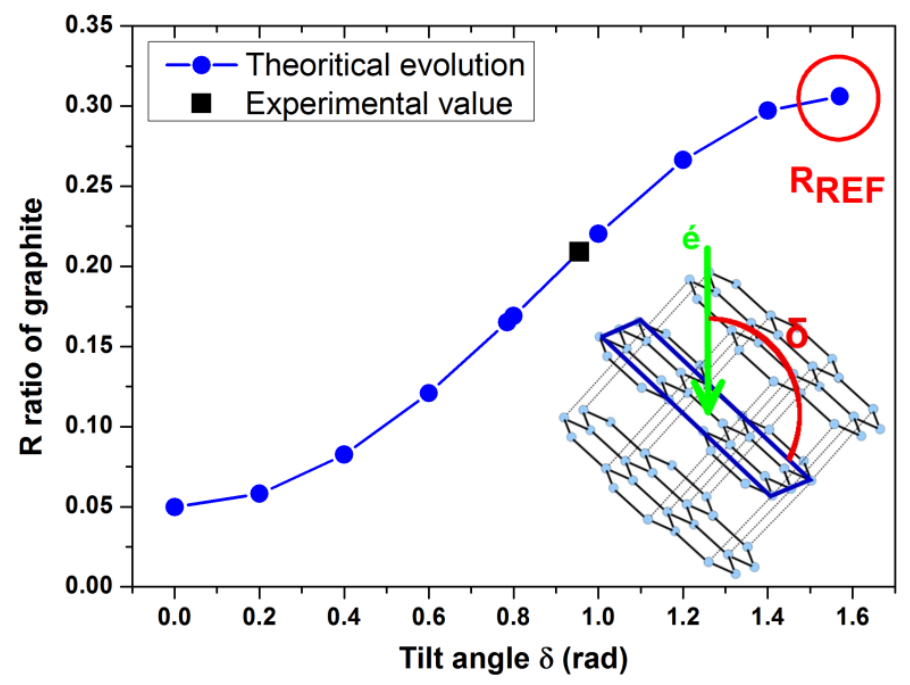

Fig. 2 Variation of the $R$ ratio as a function of the tilt angle, $\delta . \delta$ is the angle between the graphite basal plane and the incident electron beam. (A color version of this figure can be viewed online).

Once the $R$ ratio was determined, the $\mathrm{sp}^{2}$ fraction of the amorphous carbons was then calculated by using the following relation $s p^{2} \%=R / R_{R E F}$ [67], where $R_{R E F}$ is the $R$ ratio obtained from a reference showing $100 \% \mathrm{sp}^{2}$ bonding. This work does not use magic angle condition because, as abovementioned, such condition at $300 \mathrm{kV}$ is nearly impossible to attain, and the obtained results show that this condition is not required, see below. $R_{R E F}$ was then chosen as the maximum $R$ value that could be obtained from an HOPG sample in the same experimental condition. For this purpose, a specific routine in Matlab was written based on the analytical expression of Bocquet et al. [75], which describes the variation of $R$ as a function of all the experimental settings (convergence angle, collection angle, tilt angle and acceleration voltage) for uniaxial materials. This expression is based on relativistic calculation of the differential scattering cross-section and its main advantage is that it needs only one experimental value of $R$ to derive $R$ for any other experimental settings. Thanks to this routine, the variation of $R$ as a function of the tilt angle (labeled as $\delta$ in the following) for graphite was derived by using 
the $R$ ratio experimentally determined from HOPG platelets tilted by $54.7^{\circ}$ (Fig. 2). According to the literature, the $R$ value determined at this angle coincides with the one that would be obtained in magic angle condition [68,75]. In addition, this angle, which is nearly the maximum angle experimentally that can be obtained, has been chosen to minimize the uncertainty on the determination of $R$, as it lies close to the center $R=f(\delta)$ curve. As it can be seen from Fig. 2, the maximum value of $R$ is obtained for $\delta=\pi / 2$ rad i.e. when the basal planes of graphite are parallel to the electron beam (a configuration which is experimentally impossible to obtain) and this value was used as $R_{\mathrm{REF}}$ to derive the $\mathrm{sp}^{2}$ fraction. It should be noted that this method to determine the $\mathrm{sp}^{2}$ fraction is valid only if the $\mathrm{sp}^{2}$ clusters of the a:C-H material do not show any preferential orientation at the scale of the apparent electron probe during the EELS acquisition (20 nm $\times 20 \mathrm{~nm}$ in this work). This has been tested by checking that there is no variation of $\mathrm{sp}^{2}$ fraction as a function of tilt angle for the amorphous carbon samples. Finally the most representative core-loss spectra were submitted to the open-access EELS Database as references [81].

In addition to core-loss spectra, low-loss spectra were also acquired to determine the mass density of such samples. For this purpose, the low-loss spectra were deconvoluted by the ZLP by using the PEELS program [82] and the single-scattering spectra were obtained following Stephen's procedure [83]. For each spectrum, the $(\pi+\sigma)$ volume plasmon was then modeled over the top $75 \%$ of the plasmon peak intensity in order to extract the plasmon energy, $E_{P}$ (see Fig. S2 in the Supplementary Data). By assuming that carbon contributes to four valence electrons, oxygen to six and hydrogen to one, the following relationship was then derived by linking the mass density with the valence electron density [41,57]:

$$
\rho=\frac{E_{P}^{n} \times m^{*} \times \epsilon_{0} \times \mu \times\left(12 X_{C}+16 X_{0}+X_{H}\right)}{k^{2} \times e^{2} \times\left(4 X_{C}+6 X_{0}+X_{H}\right)}(\text { Eq. } 1)
$$


Where $\rho$ is the mass density, $E_{P}$ is the plasmon energy determined by the Drude model, $\varepsilon_{0}$ the vacuum permittivity, $\mu$ the atomic mass unit, $e$ the elementary charge, $k$ the reduced Planck constant, $X_{H}$ the hydrogen fraction determined by Raman spectroscopy, $X_{O}$ the oxygen fraction determined by EELS (and by assuming that $X_{C}+X_{O}+X_{H}=1$ ) and $m^{*}$ the effective electron band mass taken as $m^{*}=0.87 m[57,59,84]$.

\section{RESULTS}

\subsection{Raman and EELS spectra}

Raman spectroscopy has been used for getting different information, as for retrieving the $\mathrm{H}$-content, as the $\mathrm{H}_{\mathrm{D}} / \mathrm{H}_{\mathrm{G}}$ ratio of a-C:H layers can be related to the $\mathrm{H}$-concentration better than the $\mathrm{m} / \mathrm{H}_{\mathrm{G}}$ ratio [19]. In the Fig. S3 of the Supplementary Data, the calibration method used to determine the hydrogen content by monitoring the evolution of the $\mathrm{H}_{\mathrm{D}} / \mathrm{H}_{\mathrm{G}}$ for a set of reference samples using wavelengths of 407, 514 and $633 \mathrm{~nm}$ is detailed. Below the variation of the other spectroscopic parameters of the samples will be discussed as they give complementary qualitative information and trends about disorder in the material. 


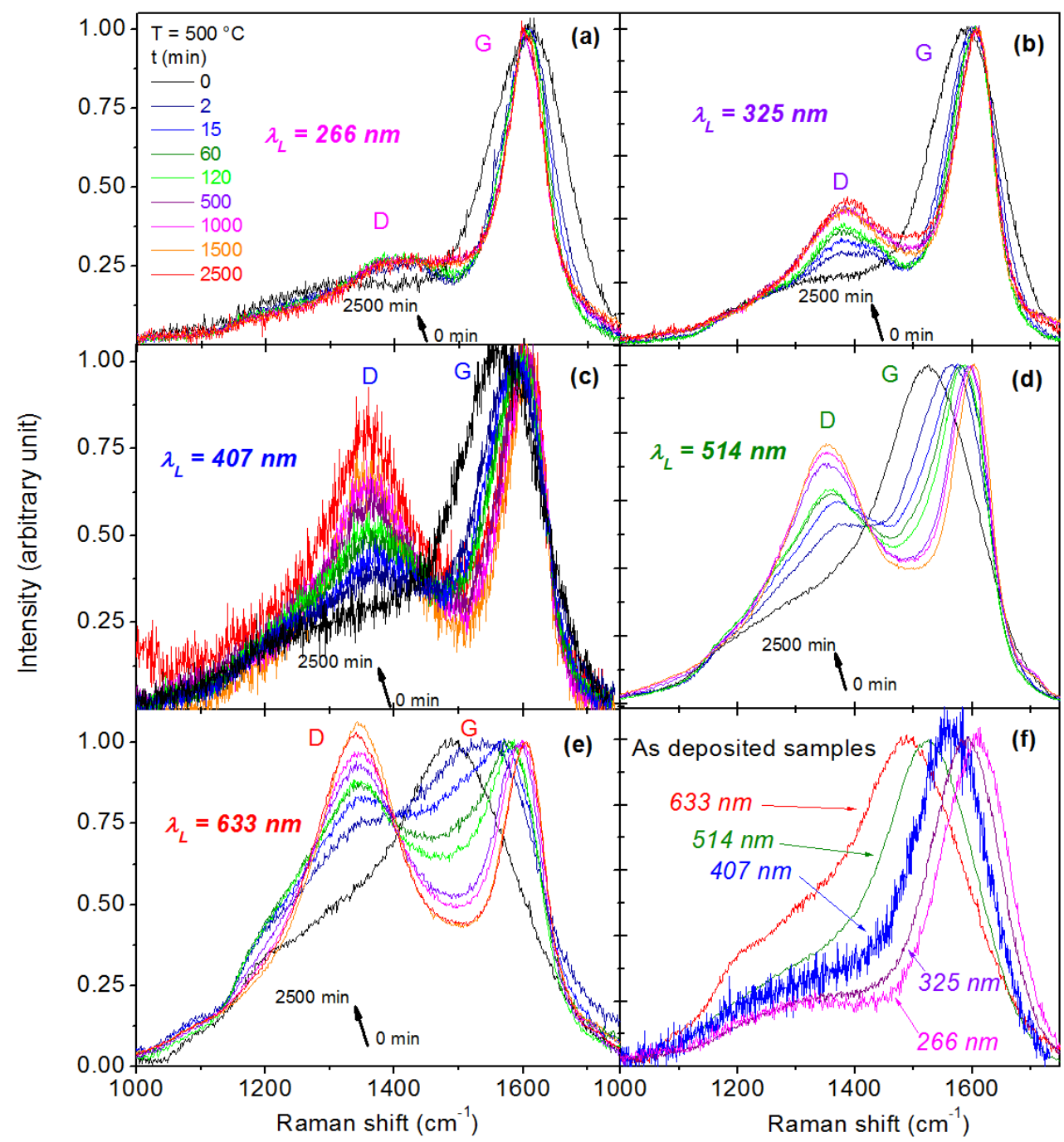

Fig. 3 Raman spectra of the a-C:H samples heated at $500^{\circ} \mathrm{C}$ during 0 to 1500 minutes. (a) Spectra using a $\lambda_{\mathrm{L}}=266 \mathrm{~nm}$ laser. (b) Spectra using a $\lambda_{\mathrm{L}}=325 \mathrm{~nm}$ laser. (c) Spectra using a $\lambda_{\mathrm{L}}=407 \mathrm{~nm}$ laser. (d) Spectra using a $\lambda_{\mathrm{L}}=514 \mathrm{~nm}$ laser. (e) Spectra using a $\lambda_{\mathrm{L}}=633 \mathrm{~nm}$ laser. (f) As-deposited samples using all the lasers. (A color version of this figure can be viewed online)

Fig. 3 displays the Raman spectra of the a-C:H samples heated at $500^{\circ} \mathrm{C}$ during 0 to 2500 minutes under argon atmosphere. From Fig. 3a to Fig. 3e these spectra are displayed increasing wavelength of the laser used from $266 \mathrm{~nm}$ to $633 \mathrm{~nm}$, respectively. Due to the resonance mechanism occurring between the incident light and the band gap produced by $\mathrm{sp}^{2}$ atoms embedded in small aromatic clusters, spectra of a given sample looks different depending on the 
wavelength of the laser used [85]. Two general trends on all these sub-figures are: first, all the spectra contain two main bands (the G and D bands of amorphous carbons), second, when time of heating increases, the $\mathrm{D}$ over $\mathrm{G}$ band ratio increases. This latest effect is associated to a bandwidth decrease. Except for Fig. 3a, where a redshift of $\sigma_{G}$ is observed with time, the increase and decrease with time of respectively $\mathrm{H}_{\mathrm{D}} / \mathrm{H}_{\mathrm{G}}$ and $\Gamma_{\mathrm{G}}$ are also accompanied by a $\sigma_{\mathrm{G}}$ blue-shift, as reported first in [86] for heated amorphous carbons. Fig. 3f displays the spectra of the as deposited samples, showing a blue-shift and narrowing of the $G$ band and a decrease of the $H_{D} / H_{G}$ ratio with the decrease of the laser wavelength, as expected from [26]. The shape of all these spectra gives qualitative information: the isothermal heating produces structural changes, but the level of disorder remains high in the material after heating, as the D band is still present. All the physical implications about the variation of the spectroscopic parameters are discussed below. 


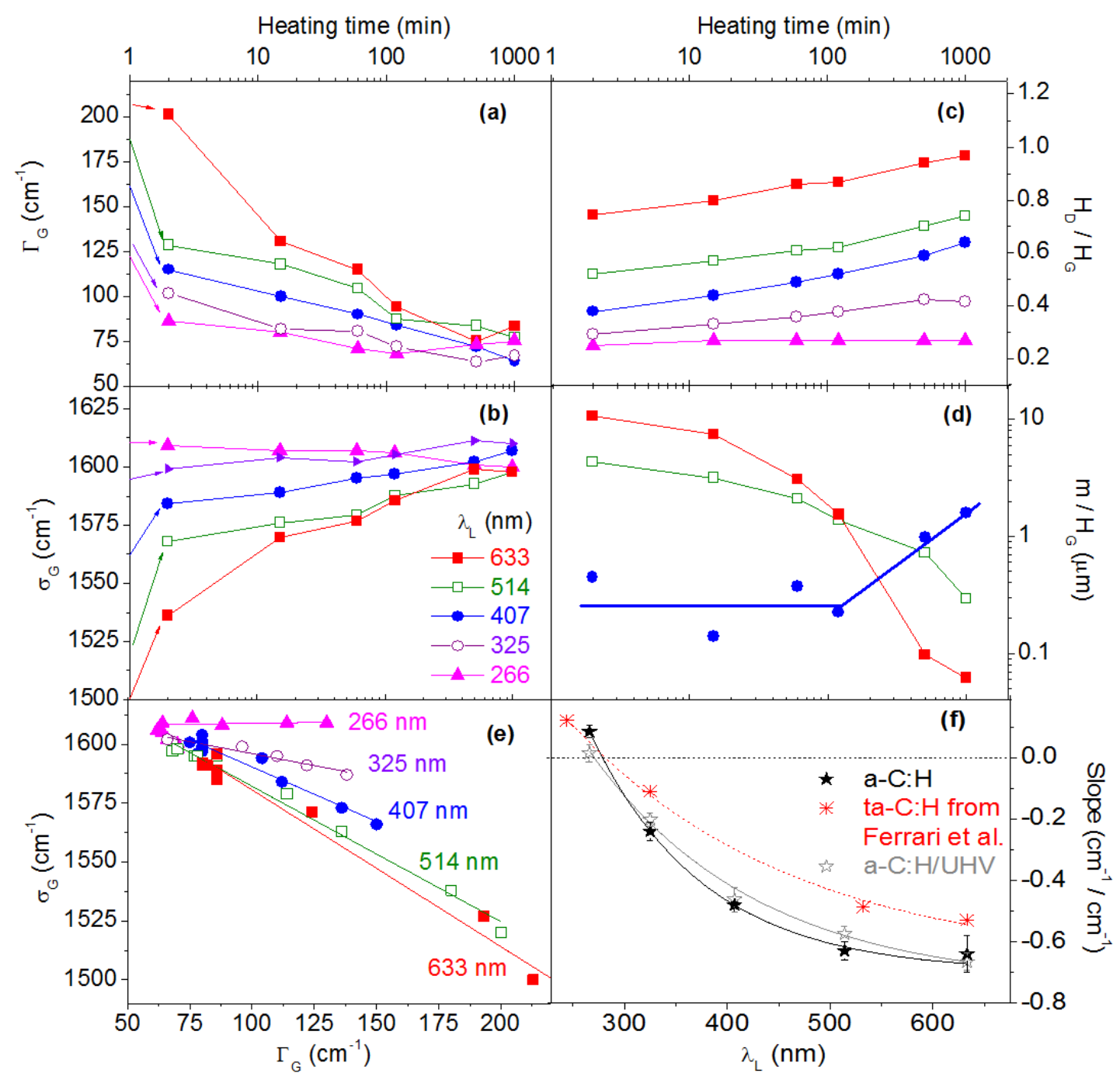

Fig. 4 -Time evolution of apparent Raman parameters of the a-C:H heated at $500^{\circ} \mathrm{C}$. Labels of sub figures $a, b, c$ and $d$ are the same and displayed only in $4 b$. The origin of each arrow in $4 a$ and $4 b$ displays the "as deposited value" at heating time $=0$ min. (a) $G$ band width $\Gamma_{G}$, (b) $G$ band position $\sigma_{G}$, (c) $\mathrm{D}$ and $\mathrm{G}$ band height ratio $\mathrm{H}_{\mathrm{D}} / \mathrm{H}_{\mathrm{G}}$ as a function of the annealing time. (d) $\mathrm{m} / \mathrm{H}_{\mathrm{G}}$ parameter, $\mathrm{m}$ being the slope of the photoluminescence background. Multi-wavelength $\sigma_{\mathrm{G}}\left(\Gamma_{\mathrm{G}}\right)$ plot. (e) Plot for samples heated at $500^{\circ} \mathrm{C}$ under argon atmosphere during 2 to 1500 minutes. (f) Slopes extracted from the curves of $4 e$. The ta-C:H measurements are taken from [26]. (A color version of this figure can be viewed online) 
Fig. 4 displays the evolution of the apparent Raman spectroscopic parameters of the aC:H sample heated at $500^{\circ} \mathrm{C}$ during 2 minutes to 2500 minutes. $\Gamma_{G}, \sigma_{G}$, and $\mathrm{H}_{\mathrm{D}} / \mathrm{H}_{\mathrm{G}}$ measured for the five laser wavelengths are displayed in Fig. 4a, 4b and 4c, respectively. The values of $\mathrm{m} / \mathrm{H}_{\mathrm{G}}$ measured for the three lowest laser wavelength are plotted in Fig. 4d. For the other wavelengths, slopes are close to zero. The time evolution of these parameters is used in Fig. 4e and $4 \mathrm{f}$ to derive the $\mathrm{H}$ content $[19,20,36]$ and the dispersion curve of the $\mathrm{G}$ band [26,27]. In Fig. 4a and $4 \mathrm{~b} \Gamma_{\mathrm{G}}$ and $\sigma_{\mathrm{G}}$, whatever the laser wavelength used, evolve rapidly between the as deposited sample and 2 minutes of heating, and then evolve monotically from 2 minutes to 1500 minutes, converging to a unique value close to $\Gamma_{\mathrm{G}} \approx 60-70 \mathrm{~cm}^{-1}$ and $\sigma_{\mathrm{G}} \approx 1600-1605 \mathrm{~cm}^{-1}$. This implies that the aromatic domain size at the end of the isoterm is a few nanometer large [27]. In addition, the convergence of the five $\sigma_{\mathrm{G}}$ curves means the small aromatic clusters leading to the resonance effect have disappeared from the sample in 1000 minutes at $500^{\circ} \mathrm{C}$ [85]. The slopes in Fig. $4 \mathrm{~b}$ are more pronounced for the higher wavelengths used.

In Fig. 4c, $H_{D} / H_{G}$ increases monotically with heating time for $\lambda_{L}=633,514$ and $407 \mathrm{~nm}$. $\mathrm{H}_{\mathrm{D}} / \mathrm{H}_{\mathrm{G}}$ is constant for $266 \mathrm{~nm}$ and saturates after 500 minutes for $325 \mathrm{~nm}$. The difference of behavior for UV and visible light is due to a strong enhancement of the UV Raman cross-section of the $\mathrm{G}$ band with the $\mathrm{H}$ content [39]. The effect of this enhancement can also be seen on the reference sample that has been heated under UHV conditions (see Fig. S3 in SI) and it implies that for wavelengths shorter than $407 \mathrm{~nm}$ (i. e. 325 and $266 \mathrm{~nm}$ here), $\mathrm{H}_{\mathrm{D}} / \mathrm{H}_{\mathrm{G}}$ cannot be used to estimate the H-content. For 633, 514 and $407 \mathrm{~nm}$, we use the linear relation existing between the $\mathrm{H}$-content and $\mathrm{H}_{\mathrm{D}} / \mathrm{H}_{\mathrm{G}}$ to determine the $\mathrm{H}$-content evolution with time (see Fig. $\mathrm{S} 3$ in Supplementary Data). 
Fig. 4(d) shows that $\mathrm{m} / \mathrm{H}_{\mathrm{G}}$ decreases for $\lambda_{\mathrm{L}}=633$ and $514 \mathrm{~nm}$ and the opposite trend is observed for $\lambda_{\mathrm{L}}=407 \mathrm{~nm}$. For $\lambda_{\mathrm{L}}=633$ and $514 \mathrm{~nm}$, the decrease has been interpreted as being due to the release of hydrogen previously bonded to a $\mathrm{sp}^{3}$ carbon atom [19]. Furthermore, the evolution of $m / \mathrm{H}_{\mathrm{G}}$ does not evolve linearly with the log of time whereas it is the case for $\mathrm{H}_{\mathrm{D}} / \mathrm{H}_{\mathrm{G}}$. This difference of behavior suggests that $\mathrm{H}$ bonded to $\mathrm{sp}^{3}$ carbon is released more easily than $\mathrm{H}$ bonded to $\mathrm{sp}^{2}$ carbon [19]. The increase of $\mathrm{m} / \mathrm{H}_{\mathrm{G}}$ for $\mathrm{t}>100$ minutes using $\lambda_{\mathrm{L}}=407 \mathrm{~nm}$ shows that there is an increase of photoluminescence in the material. The interpretation of this result is not clear yet, but it could be due to an experimental bias as a result of the change of the absorption coefficient of the layer with the wavelength: whereas the Raman signature of the underlying silicon wafer is seen during all the kinetic experiments carried out at 633 and $514 \mathrm{~nm}$ (not shown here but proving the laser probes all the thickness), it is not the case for shorter wavelengths, meaning Raman spectroscopy only probes a part of the sample far from the silicon/carbon interface at these wavelength. As it will be shown later, the surface starts to be polluted by oxygen for 1000 and 2500 minutes so that the $\mathrm{m} / \mathrm{H}_{\mathrm{G}}$ increase can be due to photoluminescence created by oxygen impurity close to the surface. This last point is supported by the fact that such a $\mathrm{m} / \mathrm{H}_{\mathrm{G}}$ with $\lambda_{\mathrm{L}}=407 \mathrm{~nm}$ has not been observed for the reference sample that has been heat treated under UHV conditions (see Fig. S3 in the Supplementary Data).

Fig. 4e displays the comparison of multi-wavelength $\sigma_{\mathrm{G}}\left(\Gamma_{\mathrm{G}}\right)$ plots samples heated at 500 ${ }^{\circ} \mathrm{C}$ during 2 to 1500 minutes under argon atmosphere. The behavior is the same for all the different excitation wavelengths (except for $266 \mathrm{~nm}$ ): increasing time results in moving from the down right corner to the up left corner. The same trends are observed when plotting $\sigma_{\mathrm{G}}$ in function of $\Gamma_{\mathrm{G}}$ for the reference samples that have been heated under UHV conditions up to $1000^{\circ} \mathrm{C}$ (not shown here). Thus, it means that the two spectroscopic parameters, $\sigma_{\mathrm{G}}$ and $\Gamma_{\mathrm{G}}$, 
independently of the annealing method, are related each other. Slopes corresponding to all the wavelength are compared in Fig. 4f with that of ta-C:H sample (data taken from [26]), known to contain more $\mathrm{sp}^{3}$ carbons than a-C:H sample. The evolution of this slope with $\lambda_{\mathrm{L}}$ is more pronounced for the a-C:H sample than that for the ta-C:H sample. The origin of that may be due to the difference in the coupling between $\mathrm{sp}^{2}$ and $\mathrm{sp}^{3}$ carbons in a-C:H and ta- $\mathrm{C}: \mathrm{H}$, but it as to be tested on other materials.

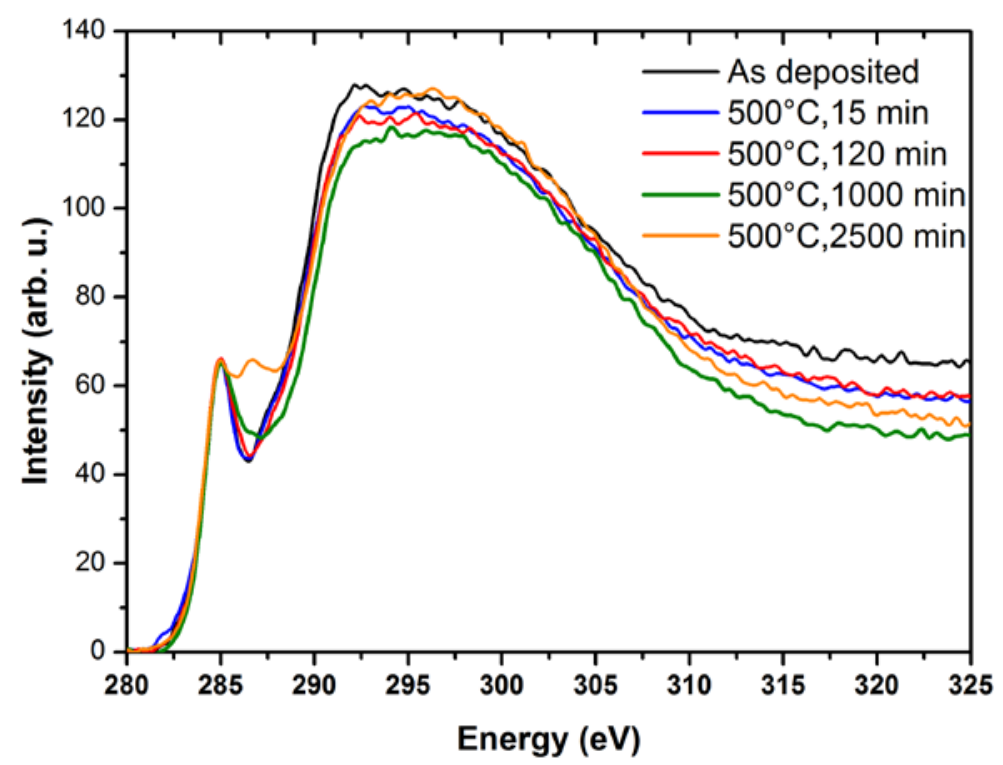

Fig. 5 -C-K edge energy-loss near edge fine structures for the as-deposited and annealed samples. (A color version of this figure can be viewed online)

Fig. 5 shows the most representative EELS spectra for the as-deposited and annealed samples. All these spectra show similar fine-structures: the $\pi^{*}$ peak is clearly visible around 285 $\mathrm{eV}$ and the massif between 290 and $305 \mathrm{eV}$ is nearly featureless. This is a typical signature of amorphous carbons [23,48]. The main striking feature of Fig. 5 lies in the intensity of the massif between 290 and $305 \mathrm{eV}$, which differs from sample to sample and which clearly highlights a slight variation of the $\mathrm{sp}^{2}$ fraction. Indeed, to give a qualitative indicator of the $\mathrm{sp}^{2}$ fraction, the spectra have been normalized for displaying the same maximum intensity of the $\pi^{*}$ peak. In 
addition, samples with the longest annealing time do not show the typical fine-structures of a perfect, pure and high quality $\mathrm{sp}^{2}$ material (green arrows in Fig. 1) and then, it can be excluded that a full graphitization process occurred during the annealing. However a more detailed analysis (see below) shows the real different variations between all these samples, which is much more complex than the one displayed in Fig. 5. In particular, variations of the fine-structures near of the edge (ELNES) are observed for the as-deposited sample and samples annealed during 1000 and 2500 minutes. These changes are related to chemical inhomogeneities, having different origins. The most significant change between them is the supplementary peak around $287 \mathrm{eV}$ for the sample annealed during 2500 min which leads to an increase of the intensity between $\pi^{*}$ peak and the $\sigma^{*}$ massif starting around $292 \mathrm{eV}$. All these chemical inhomogeneities will be discussed in detail in Section 4.2

\section{DISCUSSION}

\subsection{Macroscopic evolution of the physical parameters}



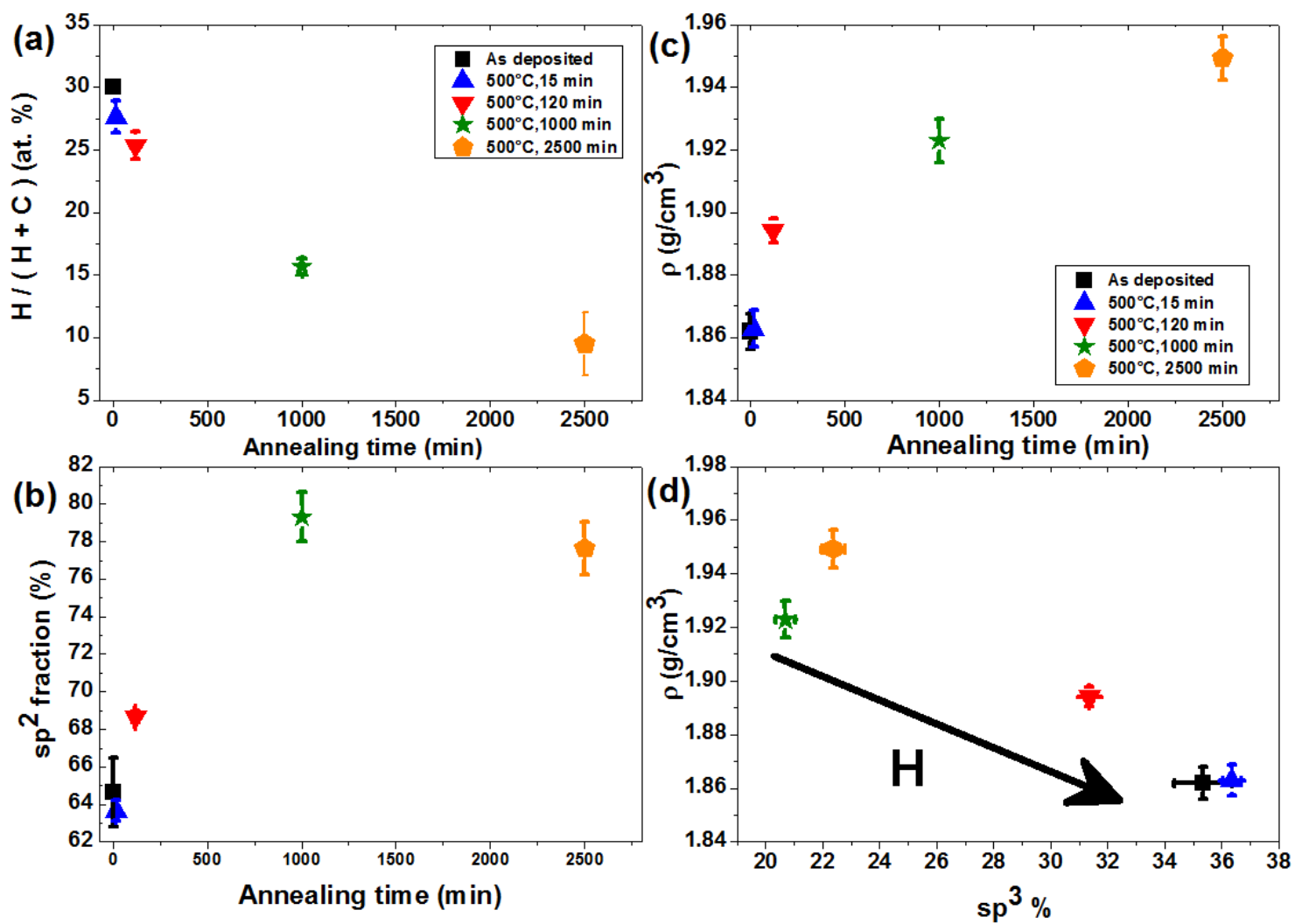

Fig. 6 -Variation of (a) hydrogen content, measured by Raman spectroscopy (the error bars represent the dispersion of measures using the three laser wavelength) and (b) $\mathrm{sp}^{2}$ fraction and determined by EELS with the annealing time. Variation of mass density (c) with annealing time (d) and with $\mathrm{sp}^{3}$ fraction. (A color version of this figure can be viewed online)

The hydrogen content $(\mathrm{H} /(\mathrm{H}+\mathrm{C}))$, determined from Raman spectroscopy, is shown in Fig. 6a. It is equal to $30 \%$ for the as-deposited sample and then decreases to reach a value of nearly $9 \%$ for the sample annealed during $2500 \mathrm{~min}$. As already reported in the literature, the annealing of hydrogenated amorphous samples leads to hydrogen desorption from the thin films [87]. Fig. 6b shows the variation of the $\mathrm{sp}^{2}$ fraction with the annealing time. This curve is divided in three steps: (I): between 0 and $15 \mathrm{~min}$, (II): between 15 and $1000 \mathrm{~min}$, and (III): between 1000 and 2500 minutes. For each of these sections, different processes, modifying the $\mathrm{sp}^{2}$ fraction are taking place. Between 0 and 15 minutes, the value of the $\mathrm{sp}^{2}$ fraction decreases from $64.7 \pm 1.8$ 
$\%$ to $63.7 \pm 0.6 \%$. However, this variation is within the experimental error and is not statically significant due to the strong inhomogeneity of the as-deposited sample (section 4.2). Between 15 and 1000 minutes, the $\mathrm{sp}^{2}$ fraction slowly increases from $63.7 \pm 0.6 \%$ to $79.3 \pm 1.3 \%$. This is consistent with the weak ELNES variations discussed before. Furthermore, this fact highlights the subtle influence of isothermal annealing at $500^{\circ} \mathrm{C}$, which triggers a slight but controllable conversion of $\mathrm{sp}^{3}$ domains to $\mathrm{sp}^{2}$ clusters. After a treatment of 2500 minutes, the $\mathrm{sp}^{2}$ fraction is equal to $77.7 \pm 1.4 \%$. Taking into account the experimental error, this value is close to the one at 1000 min. However it might also reflects the overall oxidation of the thin film as it will be discussed in the next section.

Fig. 6c shows the variation of the mass density with the annealing time, obtained from the low-loss EELS analyses. The value of the mass density starts from $1.862 \pm 0.006{\mathrm{~g} . \mathrm{cm}^{-3}}^{3}$ for the as-deposited samples and increase until reaching a value of $1.923 \pm 0.007 \mathrm{~g} . \mathrm{cm}^{-3}$ for the sample annealed during 1000 minutes. The densification of the thin films is then consistent with the overall increase of the $\mathrm{sp}^{2}$ fraction and hydrogen desorption, which are both observed during the step II. These values are also in good agreement with the values in literature of thin films with similar hydrogen content $[3,88]$. A further increase of the annealing time to 2500 minutes leads thus only to a slight increase of the mass density $\left(1.949 \pm 0.007 \mathrm{~g} . \mathrm{cm}^{-3}\right)$. In fact, the increase of the plasmon energy (from $25.20 \pm 0.04 \mathrm{eV}$ to $25.36 \pm 0.05 \mathrm{eV}$ going from 1000 to $2500 \mathrm{~min})$ in Eq. 1 is compensated by the high oxygen content $\left(\mathrm{X}_{\mathrm{O}} \sim 13.2 \%\right.$, see section 4.2). However, it should be noted that this value has been calculated assuming an effective electron band mass which has been obtained from oxygen free-amorphous carbon $[57,84]$ and then we cannot exclude some differences in these amorphous carbon with samples such high oxygen content. Fig. 6d shows the variation of the density with the $\mathrm{sp}^{3}$ fraction. This plot has been used 
in the seminal work of Ferrari to distinguish the different kind of amorphous carbons [57]. For almost all the samples, the mass density decreases with the increasing of the $\mathrm{sp}^{3}$ fraction and the decreasing of the $\mathrm{H}$ fraction. This behavior is the expected for a-C:H materials, while ta-C and ta-C:H materials follow the opposite trend, for which the mass density increases with the decreasing of the $\mathrm{sp}^{3}$ fraction [57]. Two of the samples do not follow this behavior. The first one is the as-deposited sample, which contains the highest hydrogen fraction. This sample presents the lowest density but not the highest $\mathrm{sp}^{3}$ fraction. The second sample is the sample annealed during 2500 min, which contains the lowest hydrogen fraction. This sample displays the highest density but not the lowest $\mathrm{sp}^{3}$ fraction.

The deviations of these two samples from the expected behavior stresses the presence of other processes, which affect the $\mathrm{sp}^{2}$ fraction and the mass density and which cannot only be explained by macroscopic observations.

In the following sections, closer attention will be devoted to ELNES inhomogeneites, which are related to variations of the local chemical environment. In particular, these ELNES analyses will be studied as a function of the distance between the electron probe and the substrate.

\subsection{In-depth chemical inhomogeneities}




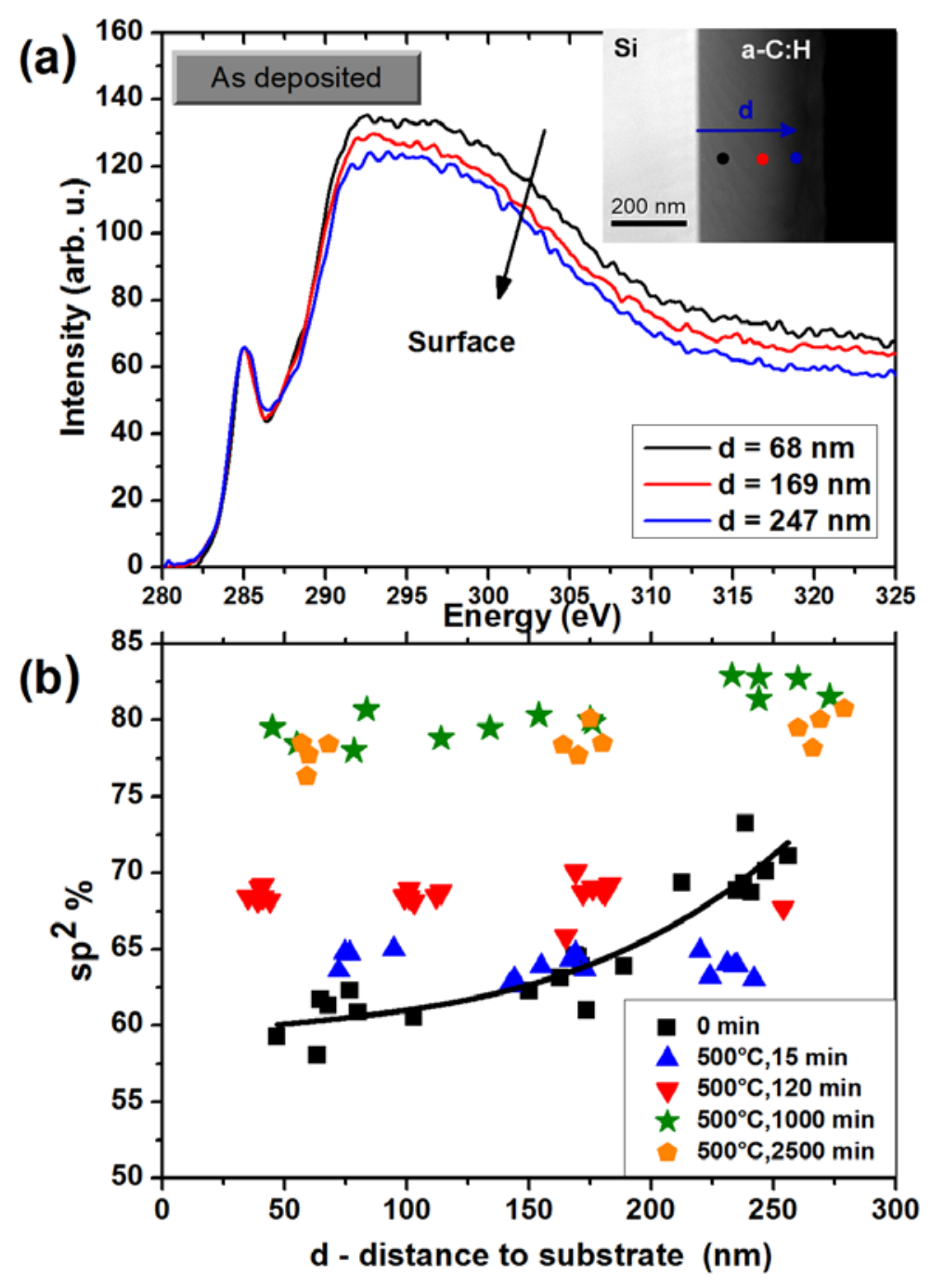

Fig. 7 (a) Variation of the C-K ELNES of the as-deposited sample with the distance to the substrate. The inset shows a low-magnification STEM-HAADF micrograph of the as-deposited sample highlighting how the $d$ parameter (distance between the electron probe and the substrate) is defined. (b) Variation of the $\mathrm{sp}^{2}$ fraction, determined by EELS, as a function of the distance between the electron probe and the substrate. The black line is a guide for the eyes. (A color version of this figure can be viewed online)

Fig. 7a shows the ELNES of the as-deposited sample as a function of the distance between the substrate and the center of the electron probe (see the low-magnification image in the inset). A clear trend is observed from this figure: the intensity of the massif situated after 292 
$\mathrm{eV}$ is lower for the spectra closer to the surface than for the spectra closer to the silicon substrate. For this sample, the $\mathrm{sp}^{2}$ fraction is thus higher closer to the surface than for the spectra closer to the substrate. This result is quantitatively confirmed by the findings presented in Fig. 7b, which correspond to the variation of $\mathrm{sp}^{2}$ fraction as a function of the distance to the silicon substrate for all the examined samples. For the as-deposited sample, the $\mathrm{sp}^{2}$ fraction close to the substrate is equal to $59 \%$ and reaches $70 \%$ close to the surface. The as-deposited sample presents then a strong gradient of $\mathrm{sp}^{2}$ fraction and this is a unique characteristic comparing the other samples and thus cannot be ascribed to irradiation damages during sample preparation and STEM-EELS observation. Macroscopic dependence of the $\mathrm{sp}^{2}$ fraction with the thickness of ultra-thin a-C:H and diamond-like thin films were already reported [89-91] and it was shown in particular that a$\mathrm{C}: \mathrm{H}$ thin films with a thickness inferior to $50 \AA$ contain more $\mathrm{sp}^{2}$ carbons [90]. Here, the opposite trend is observed, and then, another phenomenon is clearly taking place. This gradient could be induced by the deposition method and might be due to a gradient of the hydrogen fraction along the thin film or it could be induced by mechanical stress. This effect also explains why this sample could not be described by macroscopic observations. After 15 min, the annealing leads to the homogenization of the $\mathrm{sp}^{2}$ fraction along the whole thin films and the $\mathrm{sp}^{2}$ fraction increases then with the annealing time. This one illustrates directly the effect on the annealing on the local chemistry of the thin films. After 1000 minutes, the $\mathrm{sp}^{2}$ fraction reaches the maximum value of $79 \%$ and further annealing does not lead anymore to the conversion of $\mathrm{sp}^{3}$ to $\mathrm{sp}^{2}$ carbons. A slight difference close to the surface can be observed between 1000 and 2500 minutes, the $\mathrm{sp}^{2}$ fraction being lower for the sample annealed 2500 minutes than for the one annealed 1000 minutes. This sole difference explains the macroscopic decrease of the $\mathrm{sp}^{2}$ fraction reported in Fig. $6 \mathrm{~b}$ for the sample annealed 2500 minutes. The sample annealed 25000 
presents thus the same values of $\mathrm{sp}^{2}$ fraction along the whole film. However and as it will be explained in the following, this behavior hides a decrease of the $\pi^{*}(\mathrm{C}=\mathrm{C})$ contribution when going close to the surface.

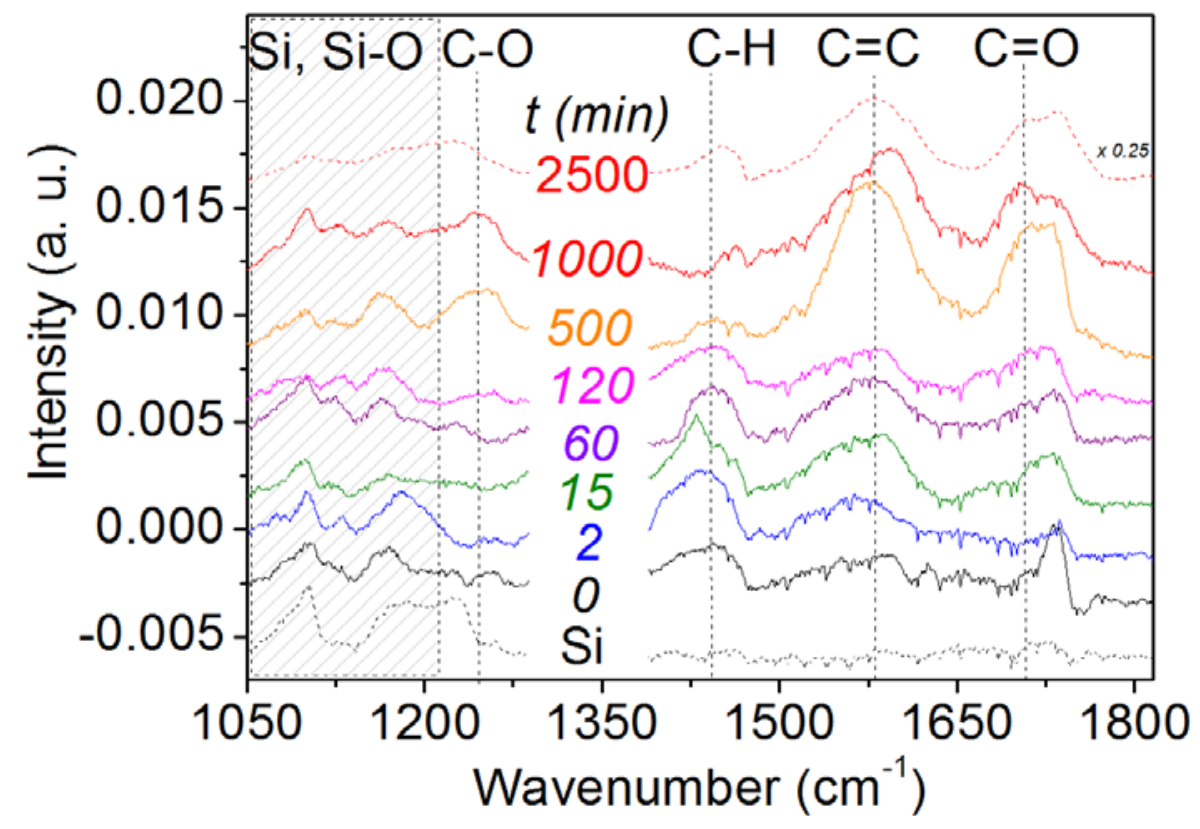

Fig. 8 ATR spectra of the a-C:H samples heated at $500^{\circ} \mathrm{C}$ during 0 to 2500 minutes. The intensity of the sample annealed during 2500 minutes is divided by a factor four in the figure. (A color version of this figure can be viewed online).

Fig. 8 displays the infrared spectra recorded using the ATR setup. The silicon wafer on which were deposited the carbon layers give rise to signatures in the spectral window 1050-1240 $\mathrm{cm}^{-1}$, thus limiting our interpretation of the carbon signatures falling in that range. On the other hand, no spectral features related to Si can be observed between 1400 and $1800 \mathrm{~cm}^{-1}$. On the asdeposited sample, three bands are lying at 1442, 1580 and $1734 \mathrm{~cm}^{-1}$. The first and second one are interpreted as due to $\mathrm{C}-\mathrm{H}$ and $\mathrm{C}=\mathrm{C}$ bonds, respectively while the third one is an artifact due 
baseline correction. When heating time increases, one can observe two new bands at 1248 and $1706 \mathrm{~cm}^{-1}$ which are due to $\mathrm{C}-\mathrm{O}$ and $\mathrm{C}=\mathrm{O}$ bonds, respectively. Compared to the band related to $\mathrm{C}=\mathrm{C}$ bonds, the intensity of the band related to $\mathrm{C}-\mathrm{H}$ bonds decreases with time, which indicates a loss of hydrogen in the a-C:H, whereas the intensity of the bands related to $\mathrm{C}-\mathrm{O}$ and $\mathrm{C}=\mathrm{O}$ bonds increases with time, which indicates an oxidation of the a-C:H. This is particularly striking for the sample annealed during 2500 minutes.

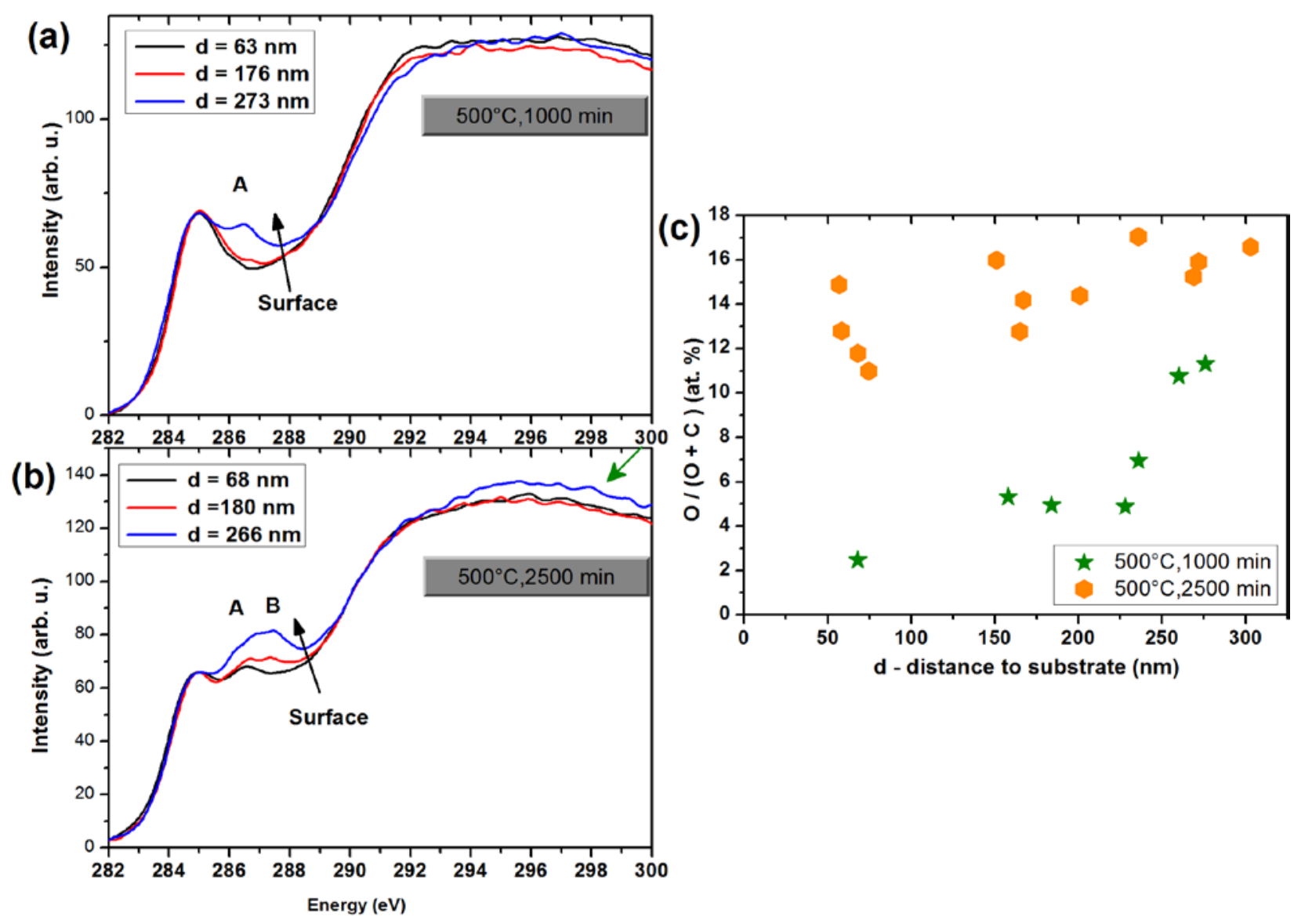

Fig. 9 ELNES of the samples annealed during 1000 minutes (a) and 2500 minutes (b). For each spectrum, the distance between the electron probe and the substrate is indicated. The green arrow highlights the increase of the $\sigma^{*}$ contribution. (c) Oxygen content as a function of the distance between the electron probe and the substrate. (A color version of this figure can be viewed 
online).

Fig. 9a and 9b show the C-K edge ELNES of the samples annealed at $500^{\circ} \mathrm{C}$ during 1000 and 2500 minutes for several distances between the electron probe and the substrate, respectively. The sample annealed during 1000 minutes presents a supplementary peak (labeled $A$ in Fig. 9a and is situated $\sim 1.6 \mathrm{eV}$ after the $\pi^{*}$ peak) which is only detected close to the surface (more than $250 \mathrm{~nm}$ from the substrate). However, this peak is always present in the spectra of the sample annealed during 2500 min, independently of the distance between the substrate and the electron probe. In addition, a supplementary peak (labeled $B$ in Fig. 9b and situated $\sim 2.4 \mathrm{eV}$ after the $\pi^{*}$ peak) is highlighted only for the samples annealed 2500 minutes and only close to the surface. According to the literature, such supplementary peaks situated right after the $\pi^{*}$ peak might be ascribed to a plethora of transitions involving heterospecies ( $\mathrm{H}$ and $\mathrm{O}$ in different bonding configurations...) and non-planar $\mathrm{sp}^{2}$-bonded carbon (i.e. fullerene-like) [78,92-97]. For instance, aromatic $\mathrm{C}-\mathrm{OH}$ group will give rises to transitions to $\pi^{*}$ states in the energy range 285.8-286.4 eV, $\mathrm{C}=\mathrm{O}$ group to transitions to $\pi^{*}$ states in the energy range $286.5-288.3 \mathrm{eV}, \mathrm{C}-\mathrm{H}$ group to transitions to $\sigma^{*}$ states in the energy range $287.6-288.2 \mathrm{eV}$ and aromatic carbonyl and carboxyl groups to transitions to $\pi^{*}$ states in the energy range $287-288.5 \mathrm{eV}[54,78,92-94,96]$. The determination of the origins of these supplementary transitions based solely on the energy position is then particularly difficult. However, in our case, these transitions are only observed on the samples having the lowest hydrogen content and it is thus unlikely that these transitions could originate from C-H groups. They are more likely to be related to transitions to $\pi^{*}$ states. For the samples annealed 1000 and 2500 minutes, a slightly modified method has thus been used for the determination of the $R$ ratio to take these contributions into account (Fig. S2 in SI). To get more insight on the oxygen content on these samples, we have performed core-loss EELS 
analyses with a larger energy dispersion $(0.5 \mathrm{eV} /$ channel $)$ for recording simultaneously the C-K and $\mathrm{O}-\mathrm{K}$ edges. The results of the $\mathrm{O} /(\mathrm{O}+\mathrm{C})$ quantification as a function of the distance between the substrate and the electron probe is shown in Fig. 9c for the samples annealed during 1000 and $2500 \mathrm{~min}$. As it can clearly be observed, the sample annealed during 1000 minutes is only oxidized at the surface $(10 \%$ of $\mathrm{O} /(\mathrm{O}+\mathrm{C})$ atomic fraction after $250 \mathrm{~nm}$ from the substrate), while the sample annealed during 2500 min is oxidized along the whole thin film. This observation matches well the behavior of the $A$ peak. Thus, we can assign the peak $A$ to $\mathrm{C}=\mathrm{O}$ groups, and the peak $B$ to aromatic carbonyl and/or carboxyl groups. These interpretations confirm previous observations performed on soot, oxidized nanodiamonds and other organic moieties [54,78,93]. The respective contributions of the $\mathrm{C}=\mathrm{C}$ groups and carbo-oxygenated groups (inducing the $A$ and $B$ peaks) in the $\pi^{*}$ character is shown in the Tab. S1 in the Supplementary Data. These assignments allow us to estimate that $\sim 6 \%$ of the $79 \%$ of $^{2}$ fraction of the sample annealed 1000 minutes corresponds to carbons linked to oxygen (the methodology to extract this information is detailed in the Supplementary Data). This effect is slightly more pronounced close to the surface and is followed by a slight increase of the $\mathrm{C}=\mathrm{C}$ contribution. Thus, this explains the small increase of the total $\mathrm{sp}^{2}$ fraction shown for this sample at the surface in Fig. 7b.

The sample annealed 2500 minutes, which shows a total $\mathrm{sp}^{2}$ fraction close to $78 \%$, presents an important contribution of carbons linked to oxygen in the $\pi^{*}$ character (nearly $10 \%$ ). This sample shows a constant total $\mathrm{sp}^{2}$ fraction along the thin film, however this is because the decrease of the $\mathrm{C}=\mathrm{C}$ contribution at the surface is compensated by an increase of the contribution of carbons linked to oxygen. The increasing contribution of the peak $B$ is thus followed by an increase of the $\sigma^{*}$ character as it can be shown on the EELS spectra (green arrow in Fig. 9b). 
Finally, the non-negligible oxygen content of these two samples helps us to understand why they do not follow the expected variation of the mass density with the $\mathrm{sp}^{3}$ fraction (Fig. 6d).

\subsection{Validity of empirical-based Raman models}

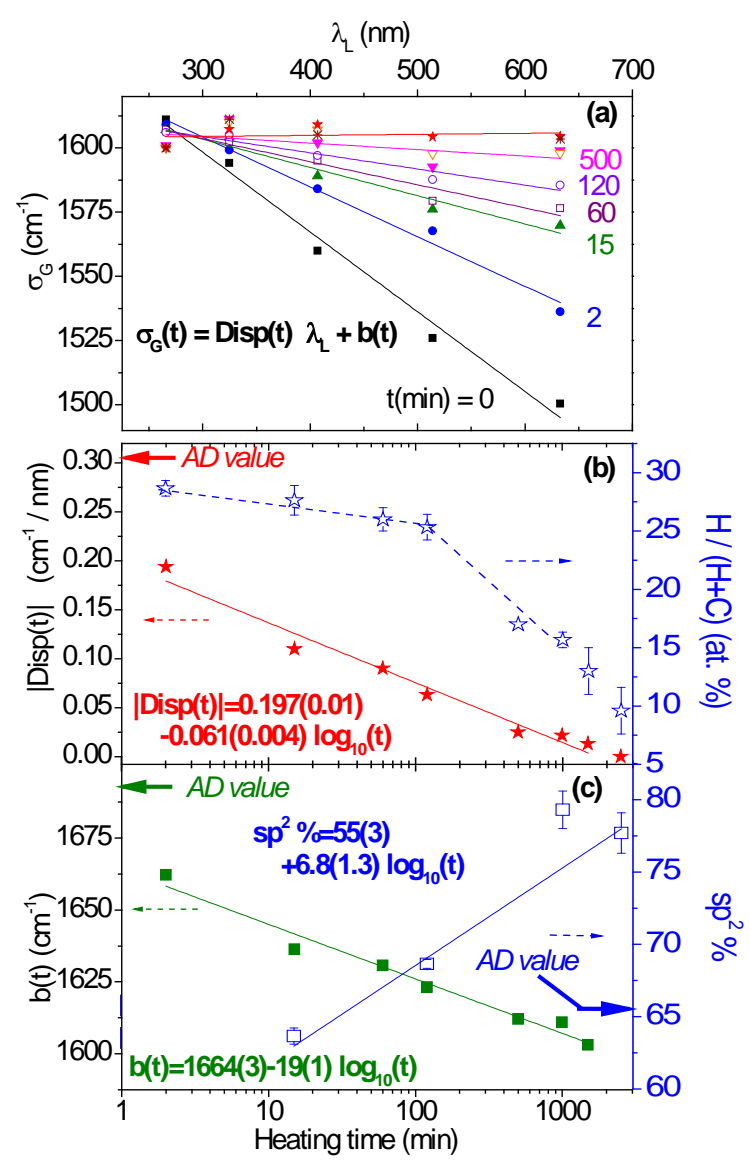

Figure 10- $G$ band dispersion compared to EELS measurements. (a) $G$ band dispersion for as deposited sample compared to heated samples (2 to 1500 minutes). Each curve has been linearly fitted. The slope (b) and the intercept (c) of the fit are displayed for all the samples. The $\mathrm{H}$-content and $\mathrm{sp}^{2}$ fraction (obtained by EELS) are also displayed, for comparison.

The EELS local analyses provide very rich information, allowing us to better understand and interpret the behavior of these materials. However, as abovementioned, multiwavelength Raman spectroscopy is a very powerful technique to determine structural and chemical 
properties of a given material, as it is a very fast method compared to other analytical techniques. As an example, an empirical relation linking the $\mathrm{sp}^{3}$ content to the $\mathrm{G}$ band dispersion was derived for as-deposited amorphous carbons [29] which however fails to extract the $\mathrm{sp}^{3}$ content for heated amorphous carbons. In addition, some care has to be taken in using formulae relating Raman spectroscopic parameters to structural and chemical properties: the spectroscopic parameters obtained by fitting depend strongly on the model used. In particular, there is an important limitation related to the fact that different kind of clusters building an amorphous carbons give spectral signatures overlapped in the same spectral range [30]. Recently Zhang et al. proposed a quantitative model showing that the dispersion of the $G$ band, weighted by three types of clusters (nc-graphite, fused aromatic rings with size less than $2 \mathrm{~nm}$ and olefinic chains), is linearly related to the $\mathrm{sp}^{3}$ content [30]. This model also supports our fittings and analytical method, consisting in taking the apparent value of the $G$ band wavenumber, $\sigma_{G}$, without fitting. For the as deposited and heated samples (2 to 1500 minutes), the dispersion curves are displayed in Fig. 10a (the 2500 minutes is not shown but the dispersion is equal to zero). The G band wavenumber for all our samples vary as $\sigma_{G}=$ Disp $\lambda_{L}+b$ (Disp being the slope and $b$ the intercept) and the absolute value of the slope diminishes with the annealing time. From this plot and following the model of Zhang et al. [30], it is possible to determine the population of $\mathrm{sp}^{2}$ carbon atoms embedded in aromatic clusters lower than $2 \mathrm{~nm}$, in aromatic clusters higher than 2 $\mathrm{nm}$ and the in olefinic chains. This yields that the $\mathrm{sp}^{2}$ carbon atoms are half embedded in aromatic clusters lower than $2 \mathrm{~nm}$ and half embedded in olefinic chains for the as-deposited sample, without carbons embedded in clusters with size higher than $2 \mathrm{~nm}$. After 2 minutes at $500^{\circ} \mathrm{C}$ sample, only $10 \%$ of $\mathrm{sp}^{2}$ carbon atoms remain in aromatic clusters of less than $2 \mathrm{~nm}$ in diameter whereas roughly $40 \%$ are now found in aromatic clusters with a size higher than $2 \mathrm{~nm}$ 
while the population of $\mathrm{sp}^{2}$ carbon atoms embedded in olefinic chains remains unchanged. The fact that aromatic ring clusters are depleted earlier/faster than the olefinic chains is also supported by the presence of a band lying as a shoulder of the $\mathrm{D}$ band at $1200 \mathrm{~cm}^{-1}$ (attributed to carbon chains, see Fig. 3), which remains in the spectrum even after 1000 minutes of heating at $500^{\circ} \mathrm{C}$. However after 10 minutes of heating the fraction of carbons embedded in aromatic clusters lower than $2 \mathrm{~nm}$ reaches unrealistic negative values (-20\% for 120 minutes).

The evolution of $\mid$ Disp $\mid$ and $b$ with the logarithm of the annealing time are displayed in Fig. 10b and 10c, respectively. They both follow a simple linear law with the logarithm of the annealing time, as suspected in [17]. Note that the R coefficient is 0.97 for both the linear fit of $|D i s p|$ and b. From Fig. 10c, similar trend is observed for the evolution of the $\mathrm{sp}^{2}$ fraction with the logarithm of the annealing time. The following linear relation between $s p^{2} \%$ and $\mid$ Disp $\mid$ can thus be determined:

$$
s p^{2} \%=74.6-86.9|\operatorname{Disp}|\left(\mathrm{cm}^{-1} / \mathrm{nm}\right)
$$

A similar linear relationship has already been reported, but with different coefficients $\left(s p^{2}\right.$ $\%=100-230|\operatorname{Disp}|\left(\mathrm{cm}^{-1} / \mathrm{nm}\right)$ in [30]). Applying this relation to our samples will lead to overestimate the $\mathrm{sp}^{2} \%$ when compared to the values obtained by EELS (75\% instead of $63 \%$ for 15 minutes, $85 \%$ instead of $68 \%$ for 120 minutes for example). In Fig. 10b, it is noteworthy that the $\mathrm{H}$ content does not follow a linear law with $\log _{10}(\mathrm{t})$ in the total range of heating times but displays a change of slope between 100 and 500 minutes, the hydrogen release being faster for $t$ $>500$ minutes. For heating time lower than 120 minutes the $\mathrm{H}$ content evolves with $\log 10(\mathrm{t})$ following :

$$
\mathrm{H} /(\mathrm{H}+\mathrm{C})\left(\text { at. \%) }=29.4(0.4)-1.90(0.26) \log _{10}(\mathrm{t})\right.
$$


A similar relationship can be derived from [30] with the same slope but with an intercept $20 \%$ lower $\left(H /(H+C)(a t . \%)=22.8(0.5)-1.92(0.31) \log _{10}(t)\right)$. It thus can stated that our work and the model of Zhang et al. [30] agree qualitatively (same trends for the different laws), but there are still some quantitative disagreement. In particular, the population of $\mathrm{sp}^{2}$ carbon atoms does not make any sense after 120 min (negative values) nor does the $\mathrm{sp}^{2}$ fraction when compared to the EELS results or the determination of the hydrogen content. Even by excluding the samples showing the higher oxygen content (1000 and 2500 minutes), the discrepancy remains. This could highlight than even a slight oxidation might have a strong influence on the Raman parameters (an increase of the bands related to infrared $\mathrm{C}=\mathrm{O}$ bonds is observed between 120 and 500 minutes). Other possibilities might involve the different methods used to determine the hydrogen content and the $\mathrm{sp}^{2}$ fraction or the fact fail to reproduce the thermal behavior of our samples which are better organized.

\section{CONCLUSION}

Hydrogenated amorphous carbon thin films on silicon substrate were submitted to an isothermal annealing up to 2500 minutes and investigated by a combination of Raman, ATR and EELS spectroscopies. In addition, a method to determine the $\mathrm{sp}^{2}$ fraction from the EELS spectra has been proposed, which does not require specific experimental setup and can include contributions from heterospecies. This fitting and analytical method shed light on the processes taking place during the thermal treatments as well as on the physical and chemical properties of the samples. A complete understanding of the local chemistry of the thin films has been made and it shed the light on the high complexity of such samples. Surprisingly, strong in-depth inhomogenities of the local chemistry has been highlighted for several samples. The as-deposited 
sample presents a strong gradient of the $\mathrm{sp}^{2}$ fraction, which is higher at the surface of thin film. An annealing of 15 minutes is enough to lead to the homogenization of the thin films and further annealing time leads a slow conversion of the $\mathrm{sp}^{3}$ domains to $\mathrm{sp}^{2}$ clusters followed by hydrogen desorption of the thin films. Starting from 1000 minutes of annealing, a slight oxidation of the whole thin film is measured at the surface of the thin film which induced the presence of another $\pi^{*}$ contribution linked to $\mathrm{C}=\mathrm{O}$ groups. Further annealing at 2500 minutes leads to an increase of the oxidation of the whole thin film and to the appearance of another $\pi^{*}$ contribution linked to aromatic carbonyl and/or carboxyl groups which is also followed by an increase of the $\sigma^{*}$ character. In addition, the possibility to extract directly quantitative information on the local chemistry solely based on the variation of Raman parameters has been investigated. Even by excluding the sample showing the higher oxidation, our work does not validate previous model

of the literature used to determine the $\mathrm{sp}^{2}$ fraction and the hydrogen content. This clearly illustrates the importance of combining several techniques to extract properly and reliably this kind of information.

\section{ACKOWLEDGMENTS}

The TEM and EELS studies were conducted at the Laboratorio de Microscopias Avanzadas, Instituto de Nanociencia de Aragon, Universidad de Zaragoza, Spain. Some of the research leading to these results has received funding from the European Union Seventh Framework Programme under Grant Agreements 312483- ESTEEM2 (Integrated Infrastructure Initiative I3) and 604391 Graphene Flagship, as well as from EU H2020 Grant Agreement 696656 Graphene Flagship. R.A. acknowledges funding from the Spanish Ministerio de Economia y Competitividad (FIS2013-46159-C3-3-P) and from EU H2020 ETN project "Enabling 
Excellence” Grant Agreement 642742. The support of the Australian Research Council's Linkage Infrastructure, Equipment and Facilities Program (LE130100119) is also gratefully acknowledged for funding the Horiba Labram Raman system.

\section{Supplementary Data}

Modified method used for the determination of the $R$ ratio taking into account the contribution of hererospecies. Low-loss EELS spectrum showing the Drude model fit used to extract the plasmon energy. Calibration curve between $\mathrm{H}_{\mathrm{D}} / \mathrm{H}_{\mathrm{G}}$ Raman parameters used in this paper to derive the $\mathrm{H}$ content. Respective contributions of the $\mathrm{C}=\mathrm{C}$ groups and carbo-oxygenated groups (related to A and B peaks) in the $\pi^{*}$ character for the samples annealed 1000 and 2500 minutes. 


\section{REFERENCES}

[1] W. Jacob, W. Möller, On the structure of thin hydrocarbon films, Appl. Phys. Lett. 63 (1993) 1771-1773.

[2] J. Robertson, Diamond-like amorphous carbon, Mater. Sci. Eng. R Rep. 37 (2002) 129281.

[3] F. Rose, N. Wang, R. Smith, Q.-F. Xiao, H. Inaba, T. Matsumura, Y. Saito, H. Matsumoto, Q. Dai, B. Marchon, others, Complete characterization by Raman spectroscopy of the structural properties of thin hydrogenated diamond-like carbon films exposed to rapid thermal annealing, J. Appl. Phys. 116 (2014) 123516.

[4] S. Takabayashi, K. Okamoto, H. Sakaue, T. Takahagi, K. Shimada, T. Nakatani, Annealing effect on the chemical structure of diamondlike carbon, J. Appl. Phys. 104 (2008) 043512.

[5] C. Casiraghi, J. Robertson, A.C. Ferrari, Diamond-like carbon for data and beer storage, Mater. Today. 10 (2007) 44-53.

[6] A. Rusanov, R. Nevshupa, J. Fontaine, J.-M. Martin, T. Le Mogne, V. Elinson, A. Lyamin, E. Roman, Probing the tribochemical degradation of hydrogenated amorphous carbon using mechanically stimulated gas emission spectroscopy, Carbon. 81 (2015) 788-799.

[7] J. Fontaine, T. Le Mogne, J. Loubet, M. Belin, Achieving superlow friction with hydrogenated amorphous carbon: some key requirements, Thin Solid Films. 482 (2005) 99108.

[8] F. Gao, A. Erdemir, W. Tysoe, The tribological properties of low-friction hydrogenated diamond-like carbon measured in ultrahigh vacuum, Tribol. Lett. 20 (2005) 221-227.

[9] H. Okubo, R. Tsuboi, S. Sasaki, Frictional properties of DLC films in low-pressure hydrogen conditions, Wear. 340 (2015) 2-8.

[10] H. Song, L. Ji, H. Li, X. Liu, H. Zhou, L. Liu, J. Chen, Interface design for aC: H film with super long wear life in high vacuum environment, Tribol. Int. 95 (2016) 298-305.

[11] Y.-N. Chen, T.-B. Ma, Z. Chen, Y.-Z. Hu, H. Wang, Combined Effects of Structural Transformation and Hydrogen Passivation on the Frictional Behaviors of Hydrogenated Amorphous Carbon Films, J. Phys. Chem. C. 119 (2015) 16148-16155.

[12] H. Ito, K. Yamamoto, M. Masuko, Thermal stability of UBM sputtered DLC coatings with various hydrogen contents, Thin Solid Films. 517 (2008) 1115-1119.

[13] D.S. Grierson, A. Sumant, A. Konicek, T. Friedmann, J. Sullivan, R.W. Carpick, Thermal stability and rehybridization of carbon bonding in tetrahedral amorphous carbon, J. Appl. Phys. 107 (2010) 033523.

[14] J.G. Buijnsters, R. Gago, A. Redondo-Cubero, I. Jimenez, Hydrogen stability in hydrogenated amorphous carbon films with polymer-like and diamond-like structure, J. Appl. Phys. 112 (2012) 093502.

[15] N. Wang, K. Komvopoulos, F. Rose, B. Marchon, Structural stability of hydrogenated amorphous carbon overcoats used in heat-assisted magnetic recording investigated by rapid thermal annealing, J. Appl. Phys. 113 (2013) 083517.

[16] M. Cloutier, C. Harnagea, P. Hale, O. Seddiki, F. Rosei, D. Mantovani, Long-term stability of hydrogenated DLC coatings: Effects of aging on the structural, chemical and mechanical properties, Diam. Relat. Mater. 48 (2014) 65-72.

[17] C. Hopf, T. Angot, E. Aréou, T. Dürbeck, W. Jacob, C. Martin, C. Pardanaud, P. Roubin, T. Schwarz-Selinger, Characterization of temperature-induced changes in amorphous hydrogenated carbon thin films, Diam. Relat. Mater. 37 (2013) 97-103. 
[18] F. Mangolini, F. Rose, J. Hilbert, R.W. Carpick, Thermally induced evolution of hydrogenated amorphous carbon, Appl. Phys. Lett. 103 (2013) 161605.

[19] C. Pardanaud, C. Martin, P. Roubin, G. Giacometti, C. Hopf, T. Schwarz-Selinger, W. Jacob, Raman spectroscopy investigation of the $\mathrm{H}$ content of heated hard amorphous carbon layers, Diam. Relat. Mater. 34 (2013) 100-104.

[20] C. Pardanaud, C. Martin, G. Giacometti, P. Roubin, B. Pégourié, C. Hopf, T. SchwarzSelinger, W. Jacob, J.G. Buijnsters, Long-term H-release of hard and intermediate between hard and soft amorphous carbon evidenced by in situ Raman microscopy under isothermal heating, Diam. Relat. Mater. 37 (2013) 92-96.

[21] S. Peter, M. Günther, O. Gordan, S. Berg, D. Zahn, T. Seyller, Experimental analysis of the thermal annealing of hard aC: H films, Diam. Relat. Mater. 45 (2014) 43-57.

[22] C. Pardanaud, C. Martin, G. Giacometti, N. Mellet, B. Pégourié, P. Roubin, Thermal stability and long term hydrogen/deuterium release from soft to hard amorphous carbon layers analyzed using in-situ Raman spectroscopy. Comparison with Tore Supra deposits, Thin Solid Films. 581 (2015) 92-98.

[23] R. Arenal, A. Liu, Clustering of aromatic rings in near-frictionless hydrogenated amorphous carbon films probed using multiwavelength Raman spectroscopy, Appl. Phys. Lett. 91 (2007) 211903.

[24] R. Arenal, G. Montagnac, P. Bruno, D. Gruen, Multiwavelength Raman spectroscopy of diamond nanowires present in n-type ultrananocrystalline films, Phys. Rev. B. 76 (2007) 245316.

[25] C. Pardanaud, C. Martin, P. Roubin, Multiwavelength Raman spectroscopy analysis of a large sampling of disordered carbons extracted from the Tore Supra tokamak, Vib. Spectrosc. 70 (2014) 187-192.

[26] A. Ferrari, J. Robertson, Resonant Raman spectroscopy of disordered, amorphous, and diamondlike carbon, Phys. Rev. B. 64 (2001) 075414.

[27] A.C. Ferrari, J. Robertson, Raman spectroscopy of amorphous, nanostructured, diamondlike carbon, and nanodiamond, Philos. Trans. R. Soc. Lond. Ser. Math. Phys. Eng. Sci. 362 (2004) 2477-2512.

[28] L.G. Cançado, A. Jorio, E.M. Ferreira, F. Stavale, C. Achete, R. Capaz, M. Moutinho, A. Lombardo, T. Kulmala, A. Ferrari, Quantifying defects in graphene via Raman spectroscopy at different excitation energies, Nano Lett. 11 (2011) 3190-3196.

[29] W. Cui, Q. Lai, L. Zhang, F. Wang, Quantitative measurements of sp 3 content in DLC films with Raman spectroscopy, Surf. Coat. Technol. 205 (2010) 1995-1999.

[30] L. Zhang, X. Wei, Y. Lin, F. Wang, A ternary phase diagram for amorphous carbon, Carbon. 94 (2015) 202-213.

[31] J. Robertson, E. O'reilly, Electronic and atomic structure of amorphous carbon, Phys. Rev. B. 35 (1987) 2946.

[32] J. Robertson, Electronic processes in hydrogenated amorphous carbon, J. Non-Cryst. Solids. 198 (1996) 615-618.

[33] J. Wagner, M. Ramsteiner, C. Wild, P. Koidl, Resonant Raman scattering of amorphous carbon and polycrystalline diamond films, Phys. Rev. B. 40 (1989) 1817.

[34] A. Rao, E. Richter, S. Bandow, B. Chase, P. Eklund, K. Williams, S. Fang, K. Subbaswamy, M. Menon, A. Thess, others, Diameter-selective Raman scattering from vibrational modes in carbon nanotubes, Science. 275 (1997) 187-191. 
[35] A. Jorio, R. Saito, J. Hafner, C. Lieber, M. Hunter, T. McClure, G. Dresselhaus, M. Dresselhaus, Structural (n, $\mathrm{m}$ ) determination of isolated single-wall carbon nanotubes by resonant Raman scattering, Phys. Rev. Lett. 86 (2001) 1118.

[36] C. Casiraghi, A. Ferrari, J. Robertson, Raman spectroscopy of hydrogenated amorphous carbons, Phys. Rev. B. 72 (2005) 085401.

[37] L. Cançado, A. Jorio, M. Pimenta, Measuring the absolute Raman cross section of nanographites as a function of laser energy and crystallite size, Phys. Rev. B. 76 (2007) 064304.

[38] J. Schmid, B. Grob, R. Niessner, N.P. Ivleva, Multiwavelength Raman microspectroscopy for rapid prediction of soot oxidation reactivity, Anal. Chem. 83 (2011) 1173-1179.

[39] C. Casiraghi, Effect of hydrogen on the UV Raman intensities of diamond-like carbon, Diam. Relat. Mater. 20 (2011) 120-122.

[40] D. Levshov, T. Than, R. Arenal, V. Popov, R. Parret, M. Paillet, V. Jourdain, A.A. Zahab, T. Michel, Y.I. Yuzyuk, others, Experimental evidence of a mechanical coupling between layers in an individual double-walled carbon nanotube, Nano Lett. 11 (2011) 4800-4804.

[41] R.F. Egerton, Electron energy-loss spectroscopy in the electron microscope, Springer Science+Business Media, New York, 2011.

[42] K. Hakouk, P. Deniard, L. Lajaunie, C. Guillot-Deudon, S. Harel, Z. Wang, B. Huang, H.-J. Koo, M.-H. Whangbo, S. Jobic, others, Novel Soft-Chemistry Route of Ag2Mo3O10. 2H2O Nanowires and in Situ Photogeneration of a Ag@ Ag2Mo3O10.2H2O Plasmonic Heterostructure, Inorg. Chem. 52 (2013) 6440-6449.

[43] R. Arenal, K. March, C.P. Ewels, X. Rocquefelte, M. Kociak, A. Loiseau, O. Stéphan, Atomic Configuration of Nitrogen-Doped Single-Walled Carbon Nanotubes, Nano Lett. 14 (2014) 5509-5516.

[44] L.S. Panchakarla, L. Lajaunie, R. Tenne, R. Arenal, Atomic Structural Studies on Thin Single-Crystalline Misfit-Layered Nanotubes of TbS-CrS2, J. Phys. Chem. C. 120 (2016) 15600-15607.

[45] F.L. Deepak, A. Mayoral, R. Arenal, Advanced Transmission Electron Microscopy: Applications to Nanomaterials, Springer, 2015.

[46] R. Arenal, F. De la Pena, O. Stephan, M. Walls, M. Tence, A. Loiseau, C. Colliex, Extending the analysis of EELS spectrum-imaging data, from elemental to bond mapping in complex nanostructures, Ultramicroscopy. 109 (2008) 32-38.

[47] L.S. Panchakarla, L. Lajaunie, A. Ramasubramaniam, R. Arenal, R. Tenne, Nanotubes from Oxide-Based Misfit Family: The Case of Calcium Cobalt Oxide, ACS Nano. 10 (2016) 6248-6256.

[48] L.A. Garvie, A.J. Craven, R. Brydson, Use of electron-energy loss near-edge fine structure in the study of minerals, Am. Mineral. 79 (1994) 411-425.

[49] K.J. Livi, B. Lafferty, M. Zhu, S. Zhang, A.-C. Gaillot, D.L. Sparks, Electron energy-loss safe-dose limits for manganese valence measurements in environmentally relevant manganese oxides, Environ. Sci. Technol. 46 (2011) 970-976.

[50] Z. Wang, N. Dupré, L. Lajaunie, P. Moreau, J.F. Martin, L. Boutafa, S. Patoux, D. Guyomard, Effect of glutaric anhydride additive on the LiNi0.04Mn1.6O4 electrode/electrolyte interface evolution: A MAS NMR and TEM/EELS study, J Power Sources. 215 (2012) 170-178.

[51] H. Tan, J. Verbeeck, A. Abakumov, G. Van Tendeloo, Oxidation state and chemical shift investigation in transition metal oxides by EELS, Ultramicroscopy. 116 (2012) 24-33. 
[52] L. Lajaunie, F. Boucher, R. Dessapt, P. Moreau, Quantitative use of electron energy-loss spectroscopy Mo-M 2, 3 edges for the study of molybdenum oxides, Ultramicroscopy. 149 (2015) 1-8.

[53] P.K. Chu, L. Li, Characterization of amorphous and nanocrystalline carbon films, Mater. Chem. Phys. 96 (2006) 253-277.

[54] R. Arenal, L. De Matteis, L. Custardoy, A. Mayoral, M. Tence, V. Grazu, J.M. De La Fuente, C. Marquina, M.R. Ibarra, Spatially-resolved EELS analysis of antibody distribution on biofunctionalized magnetic nanoparticles, ACS Nano. 7 (2013) 4006-4013.

[55] K. Suenaga, M. Koshino, Atom-by-atom spectroscopy at graphene edge, Nature. 468 (2010) 1088-1090.

[56] S. Turner, Y.-G. Lu, S.D. Janssens, F. Da Pieve, D. Lamoen, J. Verbeeck, K. Haenen, P. Wagner, G. Van Tendeloo, Local boron environment in B-doped nanocrystalline diamond films, Nanoscale. 4 (2012) 5960-5964.

[57] A. Ferrari, A. Libassi, B. Tanner, V. Stolojan, J. Yuan, L. Brown, S. Rodil, B. Kleinsorge, J. Robertson, Density, sp 3 fraction, and cross-sectional structure of amorphous carbon films determined by X-ray reflectivity and electron energy-loss spectroscopy, Phys. Rev. B. 62 (2000) 11089.

[58] A. Papworth, C. Kiely, A. Burden, S. Silva, G. Amaratunga, Electron-energy-loss spectroscopy characterization of the sp 2 bonding fraction within carbon thin films, Phys. Rev. B. 62 (2000) 12628.

[59] A. Liu, R. Arenal, D. Miller, X. Chen, J. Johnson, O. Eryilmaz, A. Erdemir, J.B. Woodford, Structural order in near-frictionless hydrogenated diamondlike carbon films probed at three length scales via transmission electron microscopy, Phys. Rev. B. 75 (2007) 205402.

[60] N. Bernier, F. Bocquet, A. Allouche, W. Saikaly, C. Brosset, J. Thibault, A. Charai, A methodology to optimize the quantification of sp2 carbon fraction from $\mathrm{K}$ edge EELS spectra, J. Electron Spectrosc. Relat. Phenom. 164 (2008) 34-43.

[61] Z. Zhang, R. Brydson, Z. Aslam, S. Reddy, A. Brown, A. Westwood, B. Rand, Investigating the structure of non-graphitising carbons using electron energy loss spectroscopy in the transmission electron microscope, Carbon. 49 (2011) 5049-5063.

[62] B. Mironov, H. Freeman, A. Brown, F. Hage, A. Scott, A. Westwood, J.-P. Da Costa, P. Weisbecker, R. Brydson, Electron irradiation of nuclear graphite studied by transmission electron microscopy and electron energy loss spectroscopy, Carbon. 83 (2015) 106-117.

[63] J. Titantah, D. Lamoen, Technique for the s p 2/ s p 3 characterization of carbon materials: $\mathrm{Ab}$ initio calculation of near-edge structure in electron-energy-loss spectra, Phys. Rev. B. 70 (2004) 075115.

[64] A.-L. Hamon, J. Verbeeck, D. Schryvers, J. Benedikt, R.M. vd Sanden, ELNES study of carbon K-edge spectra of plasma deposited carbon films, J. Mater. Chem. 14 (2004) 20302035.

[65] J.J. Cuomo, J.P. Doyle, J. Bruley, J.C. Liu, Sputter deposition of dense diamond-like carbon films at low temperature, Appl. Phys. Lett. 58 (1991) 466-468.

[66] X. Zhang, R. Schneider, E. Müller, D. Gerthsen, Practical aspects of the quantification of sp 2-hybridized carbon atoms in diamond-like carbon by electron energy loss spectroscopy, Carbon. 102 (2016) 198-207.

[67] S. Berger, D. McKenzie, P. Martin, EELS analysis of vacuum arc-deposited diamond-like films, Philos. Mag. Lett. 57 (1988) 285-290. 
[68] Y. Sun, J. Yuan, Electron energy loss spectroscopy of core-electron excitation in anisotropic systems: Magic angle, magic orientation, and dichroism, Phys. Rev. B. 71 (2005) 125109.

[69] J.-C. Le Bossé, T. Epicier, B. Jouffrey, Polarization dependence in ELNES: Influence of probe convergence, collector aperture and electron beam incidence angle, Ultramicroscopy. 106 (2006) 449-460.

[70] C. Hébert, P. Schattschneider, H. Franco, B. Jouffrey, ELNES at magic angle conditions, Ultramicroscopy. 106 (2006) 1139-1143.

[71] P. Schattschneider, C. Hébert, H. Franco, B. Jouffrey, Anisotropic relativistic cross sections for inelastic electron scattering, and the magic angle, Phys. Rev. B. 72 (2005) 045142.

[72] B. Jouffrey, P. Schattschneider, C. Hébert, The magic angle: a solved mystery, Ultramicroscopy. 102 (2004) 61-66.

[73] R. Arenal, M. Kociak, N. Zaluzec, others, High-angular-resolution electron energy loss spectroscopy of hexagonal boron nitride, Appl. Phys. Lett. 90 (2007) 204105-204105.

[74] N. Menon, J. Yuan, Quantitative analysis of the effect of probe convergence on electron energy loss spectra of anisotropic materials, Ultramicroscopy. 74 (1998) 83-94.

[75] F. Bocquet, N. Bernier, W. Saikaly, C. Brosset, J. Thibault, A. Charaï, Evolution of ELNES spectra as a function of experimental settings for any uniaxial specimen: A fully relativistic study, Ultramicroscopy. 107 (2007) 81-94.

[76] C. Hopf, A. Von Keudell, W. Jacob, The influence of hydrogen ion bombardment on plasma-assisted hydrocarbon film growth, Diam. Relat. Mater. 12 (2003) 85-89.

[77] P. Reinke, G. Francz, P. Oelhafen, J. Ullmann, Structural changes in diamond and amorphous carbon induced by low-energy ion irradiation, Phys. Rev. B. 54 (1996) 7067.

[78] P. Parent, C. Laffon, I. Marhaba, D. Ferry, T. Regier, I. Ortega, B. Chazallon, Y. Carpentier, C. Focsa, Nanoscale characterization of aircraft soot: a high-resolution transmission electron microscopy, Raman spectroscopy, X-ray photoelectron and near-edge X-ray absorption spectroscopy study, Carbon. (2016).

[79] P. Mallet-Ladeira, P. Puech, P. Weisbecker, G.L. Vignoles, M. Monthioux, Behavior of Raman D band for pyrocarbons with crystallite size in the 2-5 nm range, Appl. Phys. A. 114 (2014) 759-763.

[80] K. Gross, J.P. Barragán, S. Sangiao, J. De Teresa, L. Lajaunie, R. Arenal, H.A. Calderón, P. Prieto, Electrical conductivity of oxidized-graphenic nanoplatelets obtained from bamboo: effect of the oxygen content, Nanotechnology. 27 (2016) 365708.

[81] P. Ewels, T. Sikora, V. Serin, C.P. Ewels, L. Lajaunie, A Complete Overhaul of the Electron Energy-Loss Spectroscopy and X-Ray Absorption Spectroscopy Database: eelsdb. eu, Microsc. Microanal. 22 (2016) 717-724.

[82] P. Fallon, C.A. Walsh, PEELS Program, University of Cambridge, England, PEELS Program Univ. Camb. Engl. (1996).

[83] A.P. Stephen, PhD. Thesis, University of Cambridge, England, 1980.

[84] J. Titantah, D. Lamoen, Determination of the electron effective band mass in amorphous carbon from density-functional theory calculations, Phys. Rev. B. 70 (2004) 033101.

[85] S. Matsunuma, Theoretical simulation of resonance Raman bands of amorphous carbon, Thin Solid Films. 306 (1997) 17-22.

[86] R. Dillon, J.A. Woollam, V. Katkanant, Use of Raman scattering to investigate disorder and crystallite formation in as-deposited and annealed carbon films, Phys. Rev. B. 29 (1984) 3482. 
[87] L. Calliari, M. Filippi, N. Laidani, G. Gottardi, R. Bartali, V. Micheli, M. Anderle, The role of hydrogen in the electronic structure of amorphous carbon: An electron spectroscopy study, in: Carbon, Springer, 2006: pp. 447-463.

[88] T. Schwarz-Selinger, A. Von Keudell, W. Jacob, Plasma chemical vapor deposition of hydrocarbon films: The influence of hydrocarbon source gas on the film properties, J. Appl. Phys. 86 (1999) 3988-3996.

[89] N. Soin, S.S. Roy, S.C. Ray, P. Lemoine, M.A. Rahman, P.D. Maguire, S.K. Mitra, J.A. McLaughlin, Thickness dependent electronic structure of ultra-thin tetrahedral amorphous carbon (ta-C) films, Thin Solid Films. 520 (2012) 2909-2915.

[90] F.-X. Liu, Z.-L. Wang, Thickness dependence of the structure of diamond-like carbon films by Raman spectroscopy, Surf. Coat. Technol. 203 (2009) 1829-1832.

[91] X. Li, S. Xu, P. Ke, A. Wang, Thickness dependence of properties and structure of ultrathin tetrahedral amorphous carbon films: A molecular dynamics simulation, Surf. Coat. Technol. 258 (2014) 938-942.

[92] G. Cody, H. Ade, S. Wirick, G. Mitchell, A. Davis, Determination of chemical-structural changes in vitrinite accompanying luminescence alteration using C-NEXAFS analysis, Org. Geochem. 28 (1998) 441-455.

[93] S. Osswald, G. Yushin, V. Mochalin, S.O. Kucheyev, Y. Gogotsi, Control of sp2/sp3 carbon ratio and surface chemistry of nanodiamond powders by selective oxidation in air, J. Am. Chem. Soc. 128 (2006) 11635-11642.

[94] D. D’Angelo, C. Bongiorno, M. Amato, I. Deretzis, A. La Magna, G. Compagnini, S. Spano, S. Scalese, Electron energy-loss spectra of graphene oxide for the determination of oxygen functionalities, Carbon. 93 (2015) 1034-1041.

[95] K. Varlot, J. Martin, C. Quet, EELS analysis of PMMA at high spatial resolution, Micron. 32 (2001) 371-378.

[96] J. Lehmann, B. Liang, D. Solomon, M. Lerotic, F. Luizão, J. Kinyangi, T. Schäfer, S. Wirick, C. Jacobsen, Near-edge X-ray absorption fine structure (NEXAFS) spectroscopy for mapping nano-scale distribution of organic carbon forms in soil: Application to black carbon particles, Glob. Biogeochem. Cycles. 19 (2005).

[97] S. Lee, R. Nicholls, D. Nguyen-Manh, D. Pettifor, G. Briggs, S. Lazar, D. Pankhurst, D. Cockayne, Electron energy loss spectra of C 60 and C 70 fullerenes, Chem. Phys. Lett. 404 (2005) 206-211. 


\title{
Supplementary Data for
}

\section{Advanced Spectroscopic Analyses on a:C-H Materials: Revisiting the EELS Characterization and its Coupling with multi-wavelength Raman Spectroscopy}

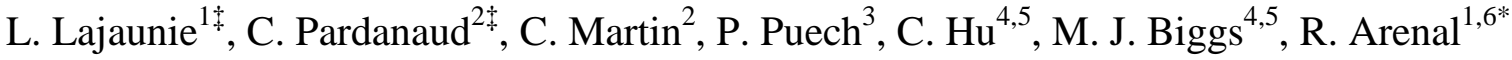 \\ ${ }^{1}$ Laboratorio de Microscopias Avanzadas (LMA), Instituto de Nanociencia de Aragon , \\ Universidad de Zaragoza, 50018 Zaragoza, Spain \\ ${ }^{2}$ Aix-Marseille Université,CNRS, PIIM, Marseille, France \\ ${ }^{3}$ CEMES, Toulouse, France \\ ${ }^{4}$ School of Chemical Engineering, The University of Adelaide, SA 5005, Australia \\ ${ }^{5}$ School of Science, Loughborough University, Loughborough, LE11 3TU, UK \\ ${ }^{6}$ Fundacion ARAID, 50018 Zaragoza, Spain
}

* Corresponding author: Tel: +34 976762 985, E-mail address: arenal@unizar.es

‡ These authors contributed equally 


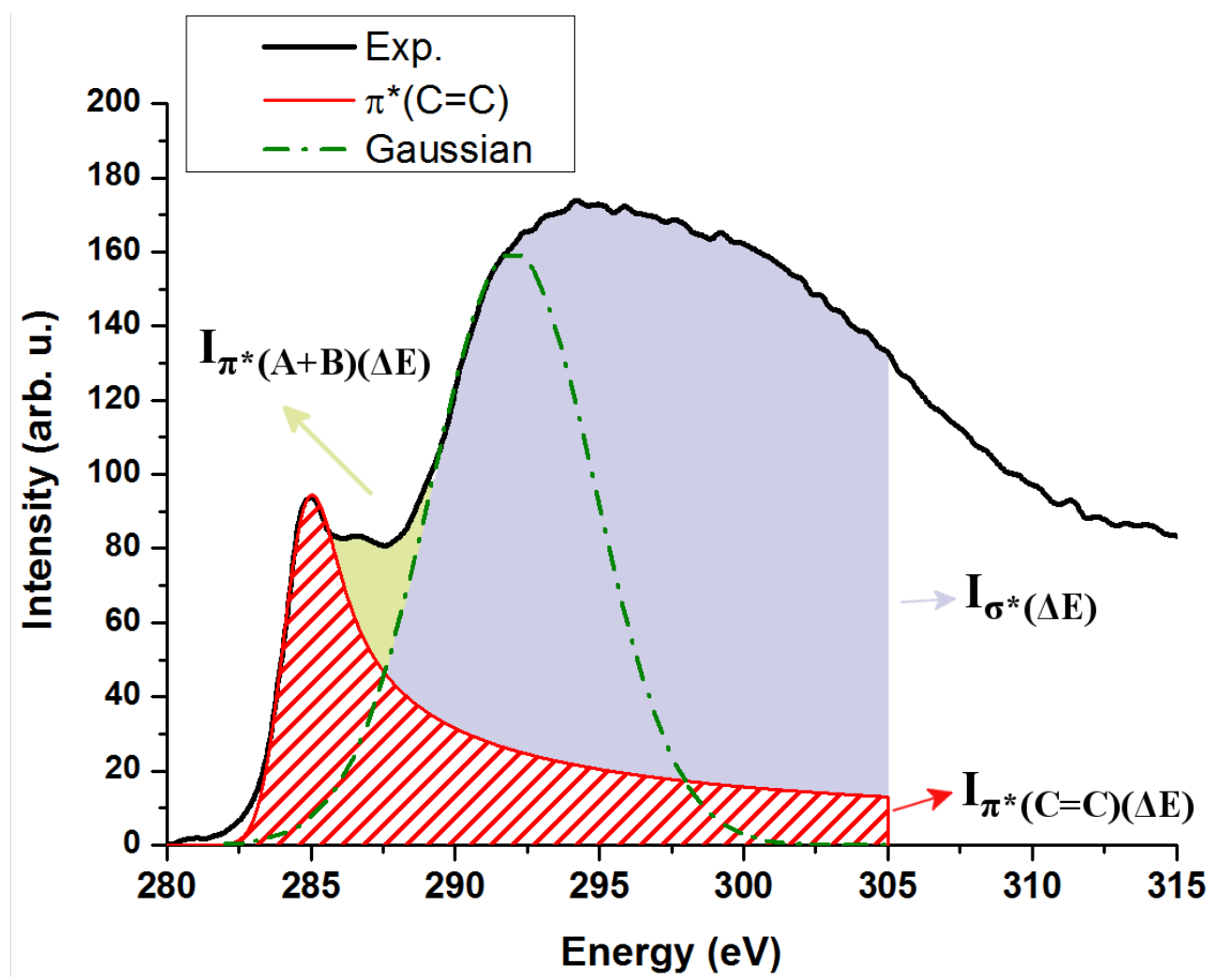

Fig. S1 Modified method used for the determination of the $R$ ratio for the samples annealed at 1000 and 25000 minutes.

Fig. S1 shows the modified method used in for the determination of the $R$ ratio for the samples annealed at 1000 and 2500 minutes. The spectral weight of the contributions $\pi^{*}(\mathrm{C}=\mathrm{C})$ is still determined by using a sum of Gaussian functions of equal standard deviation (red hatched area in Fig. S1). However, a Gaussian function centered at $292 \mathrm{eV}$ (green dot curve in Fig. S1) is introduced to reproduce the beginning of the $\sigma^{*}$ massif (blue area in Fig. S1). The spectral weight of the peaks $\mathrm{A}$ and $\mathrm{B}, \pi^{*}(\mathrm{~A}+\mathrm{B})$ (yellow area in Fig. $\mathrm{S} 1$ ), which are related to the oxygenation of the thin films is then determined by the intersection between this Gaussian function centered at $292 \mathrm{eV}$ and the $\pi^{*}(\mathrm{C}=\mathrm{C})$ contribution. Finally the total spectral weight, I

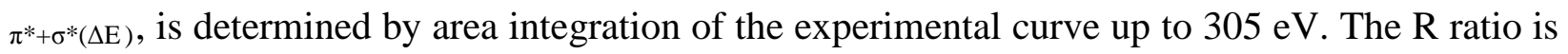
then given by $R=\left(I_{\pi^{*}(C=C)(\Delta E)}+I_{\pi^{*}(A+B)(\Delta E)}\right) / I_{\pi^{*}+\sigma^{*}(\Delta E)}$. 


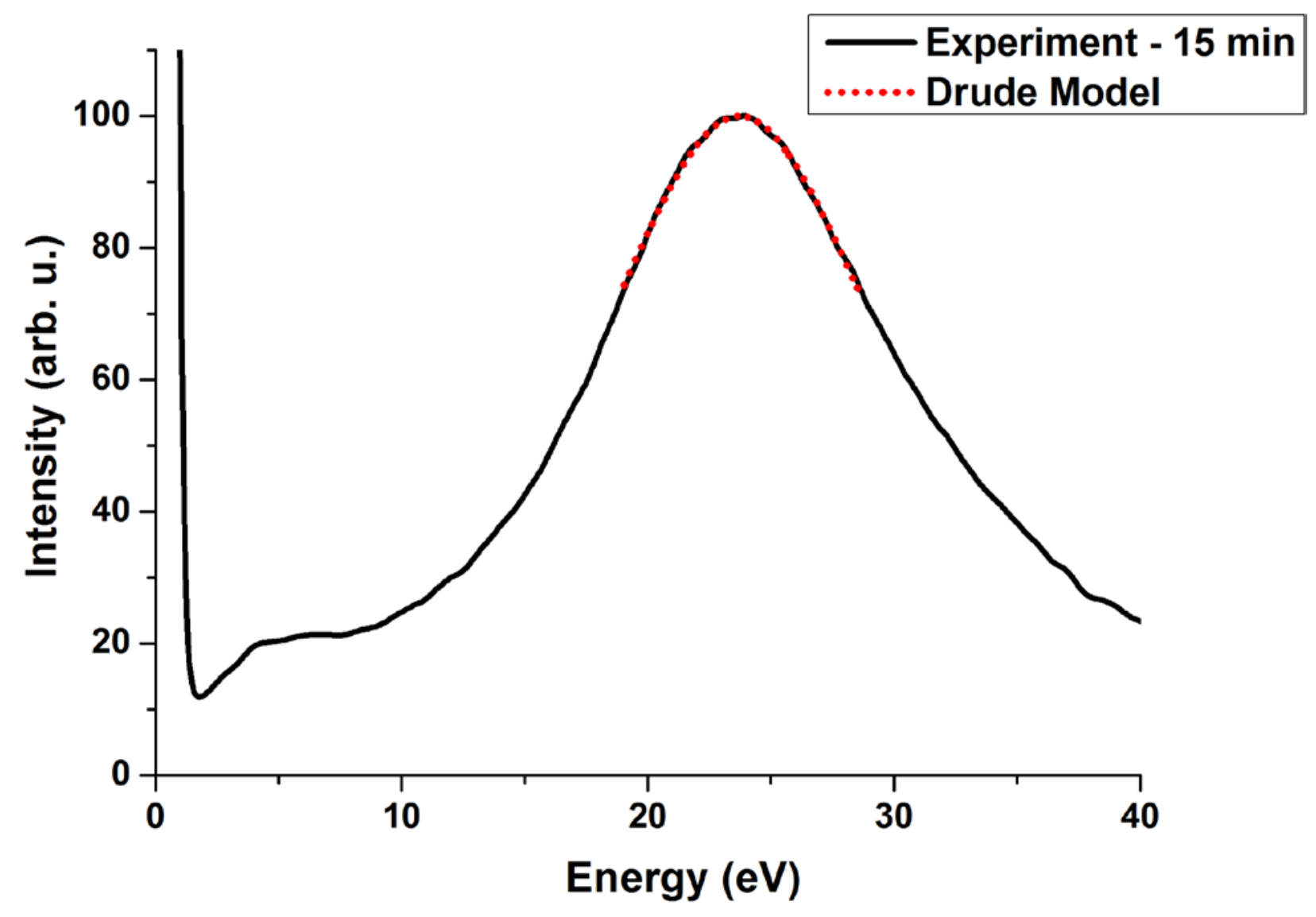

Fig. S2 Low-loss EELS spectrum of the sample annealed $15 \mathrm{~min}$. The red dotted curve corresponds to the Drude model fit used to extract the plasmon energy, $E_{P}$.

Fig. S2 shows the low-loss EELS spectrum of the samples annealed 15 min. The experimental curve (black line) has been fitted by the Drude model (red dotted line) to extract the plasmon energy, $E_{P}$, which has been used to estimate the mass density. 


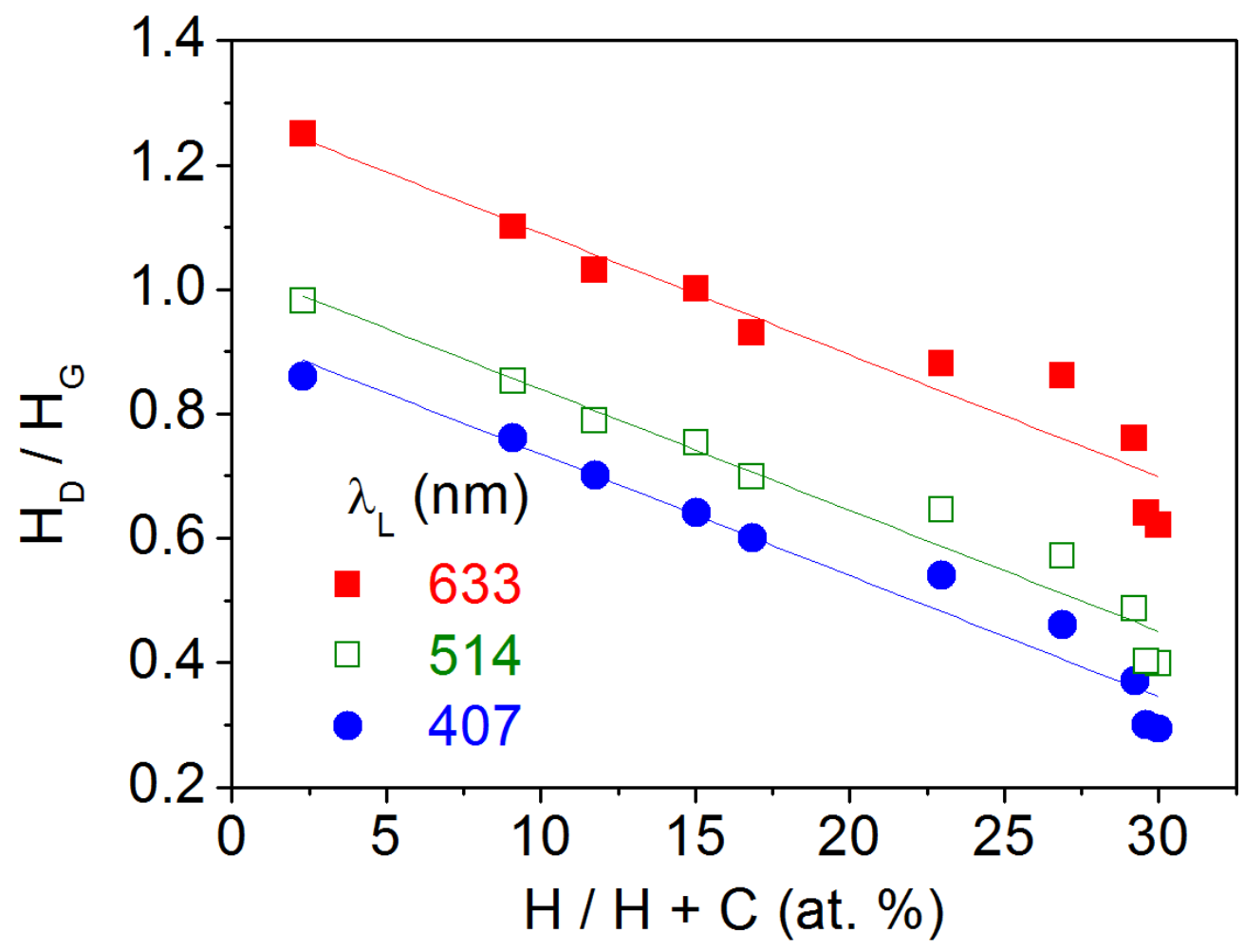

Fig. S3 Calibration curve between $\mathrm{H}_{\mathrm{D}} / \mathrm{H}_{\mathrm{G}}$ (Raman spectroscopic parameter) and the $\mathrm{H}$ content measured by ion beam analysis under ultrahigh vacuum.

The first aim of using Raman spectroscopy in this paper was to determine the H-content, following the method presented in [1], using the fact that $\mathrm{H}_{\mathrm{D}} / \mathrm{H}_{\mathrm{G}}$ evolves linearly with the $\mathrm{H}$ content for post-heated samples. The method, originally published using $\lambda_{\mathrm{L}}=514 \mathrm{~nm}$ is extended here to 633 and $407 \mathrm{~nm}$. Fig. S3 displays $\mathrm{H}_{\mathrm{D}} / \mathrm{H}_{\mathrm{G}}$ evolution in function of hydrogen content of samples heated under ultra-high vacuum and then measured by ion beam analysis (see [1] and references therein for details). For 633, 514 and $407 \mathrm{~nm} \mathrm{H}_{\mathrm{D}} / \mathrm{H}_{\mathrm{G}}$ increases linearly as the $\mathrm{H}$ content decreases, with the same slope. Only the intercept changes with the wavelength. The behavior changes for 325 and $266 \mathrm{~nm}$ (not shown here). This could be due to a change in the G band Raman cross section of a-C:H using UV laser [2]. For the samples heated in argon 
atmosphere at $500^{\circ} \mathrm{C}$ from 2 to 2500 minutes, we took the corresponding $\mathrm{H}_{\mathrm{D}} / \mathrm{H}_{\mathrm{G}}$ values presented in Fig. 4c and applied the linear relations displayed in Fig. S1 to deduce the H-content.

\begin{tabular}{|c|c|c|c|c|c|}
\hline & & $\begin{array}{l}\text { Whole } \\
\text { sample }\end{array}$ & $\mathrm{d} \sim 60 \mathrm{~nm}$ & $\mathrm{~d} \sim 160 \mathrm{~nm}$ & $\mathrm{~d} \sim 260 \mathrm{~nm}$ \\
\hline \multirow{3}{*}{1000 minutes } & $\pi^{*}(\mathrm{C}=\mathrm{C})$ & $73 \%$ & $72 \%$ & $73 \%$ & $75 \%$ \\
\hline & $\pi^{*}(\mathrm{~A}+\mathrm{B})$ & $6 \%$ & $5 \%$ & $6 \%$ & $8 \%$ \\
\hline & Total $\mathrm{sp}^{2}$ & $79 \%$ & $77 \%$ & $79 \%$ & $83 \%$ \\
\hline \multirow{3}{*}{2500 minutes } & $\pi^{*}(\mathrm{C}=\mathrm{C})$ & $67 \%$ & $70 \%$ & $68 \%$ & $66 \%$ \\
\hline & $\pi^{*}(\mathrm{~A}+\mathrm{B})$ & $11 \%$ & $9 \%$ & $11 \%$ & $12 \%$ \\
\hline & Total $\mathrm{sp}^{2}$ & $78 \%$ & $79 \%$ & $79 \%$ & $78 \%$ \\
\hline
\end{tabular}

Tab. S1 Respective contributions of the $\mathrm{C}=\mathrm{C}$ groups and carbo-oxygenated groups (related to $\mathrm{A}$ and B peaks) in the $\pi^{*}$ character for the samples annealed 1000 and 2500 minutes. The values are given for the whole samples as well as a function of the distance between the electron probe and the substrate ( $d$ parameter). The total $\mathrm{sp}^{2}$ fraction is given by $\pi^{*}(\mathrm{C}=\mathrm{C})+\pi^{*}(\mathrm{~A}+\mathrm{B})$.

\section{REFERENCES}

[1] C. Pardanaud, C. Martin, P. Roubin, G. Giacometti, C. Hopf, T. Schwarz-Selinger, W. Jacob, Raman spectroscopy investigation of the $\mathrm{H}$ content of heated hard amorphous carbon layers, Diam. Relat. Mater. 34 (2013) 100-104.

[2] C. Casiraghi, Effect of hydrogen on the UV Raman intensities of diamond-like carbon, Diam. Relat. Mater. 20 (2011) 120-122. 